Cahiers $d u$ MONDE RUSSE

\section{Cahiers du monde russe}

Russie - Empire russe - Union soviétique et États indépendants

$55 / 1-2 \mid 2014$

Fiscalité, justice et conflit politique en Russie, premier tiers du XVIIle siècle

\title{
« НА УБЫЛЫЕ МЕСТА... ВЫБИРАТЬ ОБЩЕСТВОМ»
}

К ВОПРОСУ О ПРИЧИНАХ « ШЛЯХЕТСКОГО ДВИЖЕНИЯ» НАЧАЛА 1730 Г.

"Les places vacantes... seront pourvues de façon collégiale » : des causes « du mouvement nobiliaire » du début de l'année 1730

"The assembled shall give their votes to fill vacancies": About the causes of the "nobility movement" of early 1730

\section{Sergej V. Cernikov}

\section{CpenEdition}

\section{Journals}

Édition électronique

URL : http://journals.openedition.org/monderusse/7986

DOI : $10.4000 /$ monderusse.7986

ISSN : $1777-5388$

Éditeur

Éditions de l'EHESS

Édition imprimée

Date de publication : 1 janvier 2014

Pagination : 71-95

ISBN : 9782713224409

ISSN : $1252-6576$

\section{Référence électronique}

Sergej V. Cernikov, « « На убылые места... выбирать обществом» ", Cahiers du monde russe

[Онлайн], 55/1-2 | 2014, Выложить онлайн 01 janvier 2017, Наводить справки в 30 avril 2019. URL : http://journals.openedition.org/monderusse/7986 ; DOI : 10.4000/monderusse.7986

Ce document a été généré automatiquement le 30 avril 2019.

2011 


\title{
« НА УБЫЛЫЕ МЕСТА... ВЫБИРАТЬ ОБЩЕСТВОМ»
}

\author{
К ВОПРОСУ О ПРИЧИНАХ « ШЛЯХЕТСКОГО ДВИЖЕНИЯ» НАЧАЛА 1730 Г. ${ }^{1}$ \\ "Les places vacantes... seront pourvues de façon collégiale " : des causes " du \\ mouvement nobiliaire » du début de l'année 1730 \\ "The assembled shall give their votes to fill vacancies": About the causes of the \\ "nobility movement" of early 1730
}

\section{Sergej V. Cernikov}

1 ЛИТЕРАТУРА, ПОСВЯЩЕННАЯ ПОЛИТИЧЕСКОЙ ИСТОРИИ ПОСЛЕПЕТРОВСКОЙ РОССИИ И ПОПЫТКЕ ОГРАНИЧЕНИЯ САМОДЕРЖАВИЯ НАЧАЛА 1730 Г., ВЕСЬМА ОБШИРНА². СТОЛЬ ЖЕ РАЗНООБРАЗНА ПАЛИТРА ОЦЕНОК ЭТОГО ВРЕМЕНИ, МНОГИЕ ИЗ КОТОРЫХ СЕГОДНЯ ПРЕДСТАВЛЯЮТСЯ НЕОПРАВДАННО КАТЕГОРИЧНЫМИ. ТАК, ЧАСТЬ АВТОРОВ ПРИШЛА К ВЫВОДАМ О БОРЬБЕ « СТАРОГО» И « НОВОГО» ДВОРЯНСТВА, « ПРОИЗВОЛЕ» МЕНШИКОВА ПРИ ЕКАТЕРИНЕ I, « ОЛИГАРХИИ» ДОЛГОРУКОВЫХ И ГОСПОДСТВЕ «РУССКОЙ БОЯРСКОЙ ПАРТИИ» В ЦАРСТВОВАНИЕ ПЕТРА I $^{3}$. В ОТДЕЛЬНЫХ РАБОТАХ ВСТРЕЧАЮТСЯ УТВЕРЖДЕНИЯ О НЕНАВИСТИ К ИНОЗЕМЦАМ ПРИ ПЕТРЕ II, МАССОВЫХ ОТСТАВКАХ ИНОСТРАНЦЕВ СО СЛУЖБЫ, ОТКАЗЕ ОТ ПРОДОЛЖЕНИЯ РЕФОРМ, «РАЗРУШЕНИИ» ПЕТРОВСКОЙ СИСТЕМЫ УЧРЕЖДЕНИЙ И ДАЖЕ О «ВОЗВРАТЕ К СТАРИНЕ» ${ }^{4}$ В ИЗДАНИЯХ СОВЕТСКОГО ПЕРИОДА ЗАКРЕПИЛСЯ ТЕЗИС О СОПЕРНИЧЕСТВЕ «РОДОВИТОЙ ЗНАТИ», СТАРАВШЕЙСЯ ВЕРНУТЬ СВОИ «БЫЛЫЕ ПРИВИЛЕГИИ», И «ШЛЯХЕТСТВЕ», КОТОРОЕ « ПОДДЕРЖИВАЛО АБСОЛЮТИЗМ ${ }^{5}$. ДО СИХ ПОР ОСТАЕТСЯ ПОПУЛЯРНОЙ ИНТЕРПРЕТАЦИЯ СОБЫТИЙ НАЧАЛА 1730 Г. КАК БОРЬБЫ «КОНСТИТУЦИОНАЛИСТОВ» И «СТОРОННИКОВ САМОДЕРЖАВНОЙ ФОРМЫ ПРАВЛЕНИЯ» ${ }^{6}$.

2 К НАСТОЯЩЕМУ ВРЕМЕНИ, БЛАГОДАРЯ РАБОТАМ Е.В. АНИСИМОВА, Д. РАНСЕЛА, В. КИВЕЛЬСОН, А.Б. КАМЕНСКОГО, И.В. КУРУКИНА, А.Б.ПЛОТНИКОВА И РЯДА ДРУГИХ ИССЛЕДОВАТЕЛЕЙ, ОЦЕНКИ СОБЫТИЙ НАЧАЛА 1730 Г. (КАК И ЦАРСТВОВАНИЙ ЕКАТЕРИНЫ I И ПЕТРА II В ЦЕЛОМ) ПРИОБРЕЛИ БОЛЕЕ ВЗВЕШЕННЫЙ И МЕНЕЕ ОДНОЗНАЧНЫЙ ХАРАКТЕР ${ }^{7}$. ТАКЖЕ НЕСОМНЕННЫ УСПЕХИ В ИЗУЧЕНИИ ПЕРСОНАЛЬНОГО 
СОСТАВА ПРАВЯЩЕЙ ЭЛИТЫ ЭТОГО ПЕРИОДА. ОДНАКО ЦЕЛОСТНОЕ ПРЕДСТАВЛЕНИЕ ОБ ИЗМЕНЕНИЯХ СОЦИАЛЬНОЙ СТРУКТУРЫ ЭТОГО СЛОЯ ДО СИХ ПОР ОТСУТСТВУЕТ. МЕЖДУ ТЕМ, АНАЛИЗ ДВОРЯНСКИХ ПРОЕКТОВ 1730 Г., КАК И ПРИЧИН «ШЛЯХЕТСКОГО ДВИЖЕНИЯ» В ЦЕЛОМ, НЕВОЗМОЖЕН БЕЗ УГЛУБЛЕННОГО ИЗУЧЕНИЯ « КАДРОВОЙ политики» 1725-1730 гг. ${ }^{9}$

3 КАК ИЗВЕСТНО, ПОСЛЕ СМЕРТИ ЮНОГО ПЕТРА ІІ И ПРИГЛАШЕНИЯ ВЕРХОВНЫМ ТАЙНЫМ СОВЕТОМ НА РУССКИЙ ТРОН АННЫ ИОАННОВНЫ (ВЛАСТЬ КОТОРОЙ ОГРАНИЧИВАЛАСЬ КОНДИЦИЯМИ) ВЕРХОВНИКИ СТОЛКНУЛИСЬ С ПОЛИТИЧЕСКОЙ АКТИВНОСТЬЮ ДВОРЯНСТВА И БЫЛИ ВЫНУЖДЕНЫ РАЗРЕШИТЬ СОСТАВЛЕНИЕ И ОФИЦИАЛЬНУЮ ПОДАЧУ ПРОЕКТОВ О НОВОМ ГОСУДАРСТВЕННОМ УСТРОЙСТВЕ ${ }^{10}$. ОСОБОЕ ВНИМАНИЕ В ШЛЯХЕТСКИХ « МНЕНИЯХ» УДЕЛЯЛОСЬ ПОРЯДКУ ФОРМИРОВАНИЯ ВЕРХОВНОГО ТАЙНОГО СОВЕТА, СЕНАТА, РУКОВОДСТВА КОЛЛЕГИЙ И ГУБЕРНСКОГО АППАРАТА УПРАВЛЕНИЯ ${ }^{11}$. ЛОГИЧНО ПРЕДПОЛОЖИТЬ, ЧТО ТРЕБОВАНИЯ О «СПРАВЕДЛИВОМ» РАСПРЕДЕЛЕНИИ ВЛАСТИ БЫЛИ ВЫРАЖЕНИЕМ НЕГАТИВНОЙ РЕАКЦИИ ДВОРЯНСТВА НА ЭВОЛЮЦИЮ СОСТАВА ПЕРЕЧИСЛЕННЫХ УЧРЕЖДЕНИЙ В 1725-1730 ГГ. ИЗУЧЕНИЕ ХАРАКТЕРА, НАПРАВЛЕННОСТИ И ГЛУБИНЫ ЭТИХ ПЕРЕМЕН И ЯВЛЯЕТСЯ ОСНОВНОЙ ЗАДАЧЕЙ НАСТОЯЩЕЙ РАБОТЫ.

ДЛЯ АНАЛИЗА СОЦИАЛЬНОГО ПРОФИЛЯ ЛИЦ, ВХОДИВШИХ В СОСТАВ ВЫСШИХ, ЦЕНТРАЛЬНЫХ И ГУБЕРНСКИХ УЧРЕЖДЕНИЙ, БЫЛИ ВЫДЕЛЕНЫ ПЯТЬ ГРУПП : ИНОЗЕМЦЫ И ЧЕТЫРЕ ГРУППЫ РУССКИХ В ЗАВИСИМОСТИ ОТ ПРОИСХОЖДЕНИЯ. К ЧИСЛУ БОЯРСКИХ, АРИСТОКРАТИЧЕСКИХ (ПЕРВАЯ ГРУППА) ОТНЕСЕНЫ ФАМИЛИИ, ЧЛЕНЫ КОТОРЫХ СЛУЖИЛИ В ЧИНАХ БОЯРИНА И ОКОЛЬНИЧЕГО ДО 1613 Г. И СМОГЛИ СОХРАНИТЬ ЭТО ВЫСОКОЕ ПОЛОЖЕНИЕ ПРИ РОМАНОВЫХ. ВО ВТОРУЮ ГРУППУ ВКЛЮЧЕНЫ РОДЫ, КОТОРЫЕ ДОСТИГЛИ ЛЮБОГО ИЗ ЧЕТЫРЕХ ДУМНЫХ ЧИНОВ С 1613 Г. ДО 1689 Г. В ТРЕТЬЮ ГРУППУ ВЫДЕЛЕНЫ ФАМИЛИИ, ПРЕДСТАВИТЕЛИ КОТОРЫХ БЫЛИ ДВОРЯНАМИ ИЛИ ПРИНАДЛЕЖАЛИ К ВЕРХУШКЕ ПРИКАЗНЫХ СЛУЖИТЕЛЕЙ (ДЬЯКИ), НО НЕ ВХОДИЛИ В ДУМУ ДО НАЧАЛА ПРАВЛЕНИЯ ПЕТРА І. К ЧЕТВЕРТОЙ ГРУППЕ ОТНЕСЕНЫ НЕДВОРЯНЕ ${ }^{12}$.

ОБРАТИМСЯ К СОСТАВУ ВЕРХОВНОГО ТАЙНОГО СОВЕТА. КАК ИЗВЕСТНО, ЕГО СОЗДАНИЕ СТАЛО ЛОГИЧЕСКИМ ЗАВЕРШЕНИЕМ ПЕТРОВСКОЙ РЕФОРМЫ СЕНАТА ${ }^{13}$. ПО УКАЗУ 12 ЯНВАРЯ 1722 Г. СОВМЕЩЕНИЕ ДОЛЖНОСТИ СЕНАТОРА С РУКОВОДСТВОМ В КОЛЛЕГИЯХ БЫЛО РАЗРЕШЕНО ЛИШЬ КН. А.Д. МЕНШИКОВУ, ГР. Ф.М. АПРАКСИНУ, ГР. Г.И. ГОЛОВКИНУ И БАР. П.П. ШАФИРОВУ, КОТОРЫЕ ВОЗГЛАВЛЯЛИ « ТРИ ПЕРВЫХ КОЛЛЕГИИ» (ВОЕННУЮ, АДМИРАЛТЕЙСКУЮ И ИНОСТРАННЫХ ДЕЛ), А ТАКЖЕ, В КАЧЕСТВЕ ИСКЛЮЧЕНИЯ, ГР. Я.В.БРЮСУ (БЕРГ-КОЛЛЕГИЯ) ${ }^{14}$. ОСТАЛЬНЫЕ СЕНАТОРЫ ОСВОБОЖДАЛИСЬ ОТ ПРЕЗИДЕНТСТВА, А НА ИХ МЕСТА В КОЛЛЕГИЯХ БЫЛИ ВЫБРАНЫ ДРУГИЕ ЛИЦА ${ }^{15}$. ПОСЛЕ ЭТОГО, В СЕНАТЕ ПОЯВИЛИСЬ ДВЕ КАТЕГОРИИ СЕНАТОРОВ. ОДНУ МОЖНО УСЛОВНО НАЗВАТЬ « ВЫСШЕЙ» - ОНА СОСТОЯЛА ИЗ ГЛАВ ВНЕШНЕПОЛИТИЧЕСКОГО И ВОЕННЫХ ${ }^{16}$ ВЕДОМСТВ, ДРУГУЮ « НИЗШЕЙ» - ТЕХ, КТО НЕ ИМЕЛ ПРАВА СОВМЕЩАТЬ СЕНАТОРСКУЮ ДОЛЖНОСТЬ С КОЛЛЕЖСКОЙ.

6 В ПЕРВОНАЧАЛЬНЫЙ СОСТАВ ВЕРХОВНОГО ТАЙНОГО СОВЕТА 8 ФЕВРАЛЯ 1726 Г. ВОШЛИ КН. А.Д. МЕНШИКОВ, ГР. Ф.М. АПРАКСИН, ГР. Г.И. ГОЛОВКИН, БАР. А.И. ОСТЕРМАН (ВОЗГЛАВЛЯВШИЕ «ТРИ ПЕРВЫХ» КОЛЛЕГИИ), А ТАКЖЕ КН. Д.М.ГОЛИЦЫН И ГР. П.А. ТОЛСТОЙ ${ }^{17}$. СЕНАТСКИЙ ГЕНЕРАЛ-ПРОКУРОР П.И. ЯГУЖИНСКИЙ ПОДПИСАЛ ТОЛЬКО ОДИН ПРОТОКОЛ СОВЕТА (10 ФЕВРАЛЯ $\left.1726 \Gamma^{18}\right)$, А УКАЗА О ЕГО НАЗНАЧЕНИИ НЕ ОБНАРУЖЕНО. СПУСТЯ ДЕСЯТЬ ДНЕЙ ПОСЛЕ УЧРЕЖДЕНИЯ СОВЕТА (17 ФЕВРАЛЯ 1726 Г.), В 
ЕГО СОСТАВ БЫЛ ВВЕДЕН СУПРУГ АННЫ ПЕТРОВНЫ - КАРЛ-ФРИДРИХ ГОЛШТИНСКИЙ ${ }^{19}$. ТАКИМ ОБРАЗОМ, В 1726 Г. СРЕДИ ВЕРХОВНИКОВ НАСЧИТЫВАЛОСЬ ПЯТЕРО (71\%) РУССКИХ И ДВОЕ (29\%) ИНОЗЕМЦЕВ. БОЛЬШИНСТВО РУССКИХ (3 ЧЕЛОВЕКА) ПРОИСХОДИЛИ ИЗ ФАМИЛИЙ, ПОПАВШИХ В ДУМУ ТОЛЬКО В XVII В. (II ГРУППА). ДИНАМИКА СОЦИАЛЬНОЙ СТРУКТУРЫ СОВЕТА ПРЕДСТАВЛЕНА В ТАБЛИЦЕ 1.

Таблица 1 - Состав Верховного тайного совета, 1726-1730 гг., \%

\begin{tabular}{|c|c|c|c|c|c|c|c|}
\hline ГРУППА & 1726 г. & $1727(\mathrm{E})$ & 1727(п) & 1728 г. & 1729 г. & 1730 г. & $\Delta *$ \\
\hline ИНОЗЕМЦЫ & 29 & 29 & 33 & 17 & 20 & 14 & -11 \\
\hline РУССКИЕ, І ГР. & 14 & 14 & 17 & 50 & 60 & 71 & +51 \\
\hline РУССКИЕ, ІІ ГР. & 43 & 43 & 33 & 33 & 20 & 14 & -26 \\
\hline РУССКИЕ, ІІІ ГР. & 0 & 0 & 0 & 0 & 0 & 0 & 0 \\
\hline РУсСКИЕ, IV ГР. & 14 & 14 & 17 & 0 & 0 & 0 & -14 \\
\hline итого & 100 & 100 & 100 & 100 & 100 & 100 & 0 \\
\hline В Т. Ч., РУССКИЕ І-ІІ ГР. & 57 & 57 & 50 & 83 & 80 & 86 & +26 \\
\hline
\end{tabular}

* Разность между средним значением конца периода (1729-1730 гг.) и началом периода (1726 г.).

Здесь и в следующих таблицах литерами после 1727 г. обозначены периоды правления Екатерины I - 1727(Е) и Петра II - 1727(П).

7 ПЕРЕМЕНЫ В СОВЕТЕ НАЧАЛИСЬ ВЕСНОЙ-ОСЕНЬЮ 1727 Г. : П.А. ТОЛСТОЙ И А.Д. МЕНШИКОВ ПОДВЕРГЛИСЬ ОПАЛЕ, А КАРЛ-ФРИДРИХ ГОЛШТИНСКИЙ ПОКИНУЛ РОССИЮ 20 . В НОЯБРЕ 1728 Г. СКОНЧАЛСЯ Ф.М. АПРАКСИН ${ }^{21}$. ПОПОЛНЕНИЕ СОВЕТА ОСУЩЕСТВЛЯЛОСЬ ДВАЖДЫ: 3 ФЕВРАЛЯ 1728 Г. НАЗНАЧЕНИЕ ПОЛУЧИЛИ КН. А.Г. И В.Л. ДОЛГОРУКОВЫ, А 19 ЯНВАРЯ 1730 Г. - ФЕЛЬДМАРШАЛЫ КН. М.М. ГОЛИЦЫН И КН. В.В. ДОЛГОРУКОВ ${ }^{22}$. ВСЕ ЧЕТВЕРО ПРИНАДЛЕЖАЛИ К АРИСТОКРАТИИ (І ГРУППА). ЗА СЧЕТ ЭТОГО, В 1728-1730 ГГ. ДОЛЯ ЗНАТИ РЕЗКО ВЫРОСЛА И К КОНЦУ ПЕРИОДА СОСТАВИЛА $71 \%$ ПРОТИВ $14 \%$ В 1726 г.

ЧИНОВНЫЙ СОСТАВ СОВЕТА УЖЕ СРАЗУ ПОСЛЕ ЕГО УЧРЕЖДЕНИЯ БЫЛ ДОСТАТОЧНО ОДНОРОДНЫМ. А ПОСЛЕ ТОГО, КАК ИЗ НЕГО ЛЕТОМ 1727 Г. ВЫБЫЛ ПОДПОЛКОВНИК ПРЕОБРАЖЕНСКОГО ПОЛКА К.-Ф. ГОЛШТИНСКИЙ, СРЕДИ ВЕРХОВНИКОВ ОСТАЛИСЬ ТОЛЬКО ПРЕДСТАВИТЕЛИ ДВУХ ВЫСШИХ КЛАССОВ ТАБЕЛИ О РАНГАХ 1722 Г.

9 ИЗМЕНЕНИЯ В СЕНАТЕ 1725-1730 ГГ. БЫЛИ БОЛЕЕ ЗНАЧИТЕЛЬНЫМИ ${ }^{23}$. НАЧНЕМ С АНАЛИЗА СОСТАВА СЕНАТОРОВ В КОНЦЕ 1724-НАЧАЛЕ 1725 ГГ. СВЕДЕНИЯ О ПРИСУТСТВИИ НА ЗАСЕДАНИЯХ ПРЕДСТАВЛЕНЫ В ТАБЛИЦЕ $2^{24}$. 
Таблица 2 - Участие в работе Сената (ноябрь 1724-май 1725 гг.)

\begin{tabular}{|c|c|c|c|c|c|c|c|c|c|c|c|c|c|}
\hline $\begin{array}{c}\text { Год, } \\
\text { месяп }\end{array}$ & 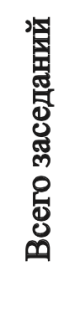 & 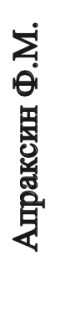 & 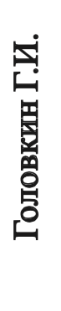 & 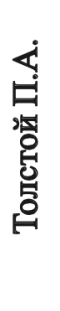 & 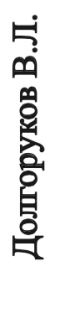 & 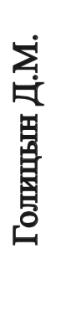 & 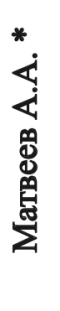 & 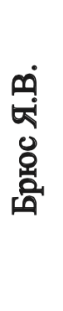 & 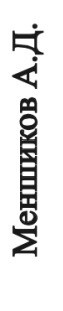 & 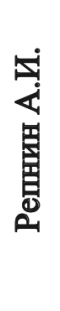 & 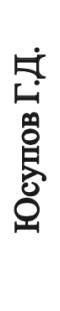 & 焉 & 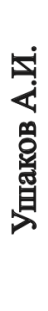 \\
\hline \multicolumn{14}{|c|}{1724 г. } \\
\hline ноябрь & 13 & 10 & 10 & 12 & - & - & - & 9 & - & 5 & - & - & - \\
\hline декабрь & 17 & 15 & 4 & 15 & - & - & - & 3 & - & 14 & 11 & 2 & - \\
\hline \multicolumn{14}{|c|}{1725 г. } \\
\hline январь & 13 & 13 & 11 & 10 & 7 & 2 & - & 8 & 1 & 8 & 5 & 1 & - \\
\hline февраль & 16 & 11 & 8 & 16 & 14 & 16 & - & 2 & 12 & 12 & 16 & 7 & 16 \\
\hline март & 11 & 11 & 6 & 10 & 9 & 9 & - & - & 7 & 8 & 11 & - & 11 \\
\hline апрель & 11 & 10 & 9 & 6 & 10 & 10 & - & 2 & 5 & - & 11 & - & 10 \\
\hline май & 16 & 15 & 16 & 11 & 7 & 16 & - & 2 & 7 & - & 14 & - & 15 \\
\hline Итого, абс. & 97 & 85 & 64 & 80 & 47 & 53 & - & 26 & 32 & 47 & 68 & 10 & 52 \\
\hline Итого, \% & 100 & 88 & 66 & 82 & 48 & 55 & - & 27 & 33 & 48 & 70 & 10 & 54 \\
\hline
\end{tabular}

*А.А. Матвеев возглавлял Сенатскую контору в Москве.

Прочерк - отсутствие данных о посещении.

Заливкой выделены случаи, когда сенатор посещал менее половины заседаний (при наличии данных).

КАК ВИДИМ, В НОЯБРЕ-ДЕКАБРЕ 1724 Г. ЗАСЕДАНИЯ СЕНАТА ПОСЕЩАЛО 7 ЧЕЛОВЕК : ГР. Ф.М. АПРАКСИН, ГР. Г.И. ГОЛОВКИН, ГР. П.А. ТОЛСТОЙ, ГР. Я.В. БРЮС, КН. А.И. РЕПНИН, КН. Г.Д. ЮСУПОВ И ГР. И.А. МУСИН-ПУШКИН. ЕЩЕ ОДИН СЕНАТОР - ГР. А.А. МАТВЕЕВ ЯВЛЯЛСЯ ПЕРВОПРИСУТСТВУЮЩИМ В МОСКОВСКОЙ СЕНАТСКОЙ КОНТОРЕ ${ }^{25}$. ИЗ ПЕРЕЧИСЛЕННЫХ ЛИЦ ДВОЕ ПОЛУЧИЛИ НАЗНАЧЕНИЕ В СЕНАТ НЕПОСРЕДСТВЕННО В 1724 Г. - КН. А.И. РЕПНИН (12 АВГУСТА 1724 Г. ${ }^{26}$ ) И КН. Г.Д. ЮСУПОВ (8 ДЕКАБРЯ 1724 Г. ${ }^{27}$ ). В ЯНВАРЕ 1725 Г., ПОМИМО УКАЗАННЫХ ВОСЬМИ СЕНАТОРОВ, НА ЗАСЕДАНИЯХ СТАЛИ ПРИСУТСТВОВАТЬ КН. В.Л. ДОЛГОРУКОВ (С 15 ЯНВАРЯ ${ }^{28}$ ), КН. Д.М. ГОЛИЦЫН (с 27 ЯНВАРЯ $\left.{ }^{29}\right)$ И КН. А.Д. МЕНШИКОВ (С 30 ЯНВАРЯ ${ }^{30}$ ).

11 ПОСЛЕ СМЕРТИ ПЕТРА ВЕЛИКОГО, В ФЕВРАЛЕ-МАЕ 1725 Г. ПОСТЫ СЕНАТОРОВ СОХРАНИЛИ Ф.М. АПРАКСИН, Г.И. ГОЛОВКИН, П.А. ТОЛСТОЙ, В.Л. ДОЛГОРУКОВ, Д.М. ГОЛИЦЫН, А.А. МАТВЕЕВ (В МОСКОВСКОЙ КОНТОРЕ), Я.В. БРЮС, А.Д. МЕНШИКОВ, А.И. РЕПНИН (ДО 19 МАРТА $^{31}$ ), Г.Д. ЮСУПОВ, И.А. МУСИН-ПУШКИН (ДО 17 ФЕВРАЛЯ ${ }^{32}$ ). С 1 ФЕВРАЛЯ 1725 Г. НОВЫМ СЕНАТОРОМ СТАЛ А.И. УШАКОВ ${ }^{33}$. ПОДЧЕРКНЕМ, ЧТО ПОВТОРЯЮЩИЕСЯ ДО СИХ ПОР В ЛИТЕРАТУРЕ УПОМИНАНИЯ О НАЗНАЧЕНИИ В СЕНАТ В ФЕВРАЛЕ 1725 Г. ГЕНЕРАЛ-АНШЕФА И.И. БУТУРЛИНА ${ }^{34}$ ЯВЛЯЮТСЯ ОШИБОЧНЫМИ. НИ ОДНОЙ ЕГО ПОДПИСИ ПОД СЕНАТСКИМИ ПРОТОКОЛАМИ ЯНВАРЯ-МАЯ 1725 Г. (А ТАКЖЕ ПОСЛЕДУЮЩЕГО ВРЕМЕНИ) НЕ ОБНАРУЖЕНО.

КАК СЛЕДУЕТ ИЗ ТАБЛИЦЫ 2, НАИБОЛЕЕ ДИСЦИПЛИНИРОВАННЫМИ СЕНАТОРАМИ В ЭТИ ГОДЫ ЯВЛЯЛИСЬ Ф.М. АПРАКСИН И П.А. ТОЛСТОЙ : ОНИ ПОСЕТИЛИ БОЛЕЕ $80 \%$ ЗАСЕДАНИЙ. Г.И. ГОЛОВКИН ПРИСУТСТВОВАЛ РЕЖЕ (66\%). НОВИЧКИ - Г.Д. ЮСУПОВ И 
А.И. УШАКОВ, - С УЧЕТОМ ИХ БОЛЕЕ ПОЗДНЕГО НАЗНАЧЕНИЯ, ПОСЕЩАЛИ СЕНАТ ВЕСЬМА РЕГУЛЯРНО. РЕЖЕ ОСТАЛЬНЫХ НА ЗАСЕДАНИЯ ПРИХОДИЛИ И.А. МУСИН-ПУШКИН (10\%), Я.В. БРЮС (27 \%) И А.Д. МЕНШИКОВ (33 \%) $)^{35}$. ПРИМЕЧАТЕЛЬНО, ЧТО СВЕТЛЕЙШИЙ КНЯЗЬ АКТИВНО УЧАСТВОВАЛ В ЗАСЕДАНИЯХ ЛИШЬ ПЕРВЫЕ ДВА МЕСЯЦА ПОСЛЕ СМЕРТИ ПЕТРА ВЕЛИКОГО - В ФЕВРАЛЕ (75\%) И МАРТЕ (64\%). В ДАЛЬНЕЙШЕМ (АПРЕЛЬ-МАЙ), ОН ОТСУТСТВОВАЛ НА БОЛЬШИНСТВЕ СЕНАТСКИХ СОБРАНИЙ.

С ИЮНЯ ПО ДЕКАБРЬ 1725 Г. В СЕНАТЕ ПРОИЗОШЛИ СЛЕДУЮЩИЕ ИЗМЕНЕНИЯ. В.Л. ДОЛГОРУКОВ БЫЛ НАЗНАЧЕН ПОСЛОМ В ВАРШАВУ И ПОСЛЕ 2 ИЮНЯ ПРОТОКОЛОВ УЖЕ НЕ ПОДПИСЫВАЛ ${ }^{36}$. С 5 ИЮЛЯ И.А. МУСИН-ПУШКИН ВОЗГЛАВИЛ МОСКОВСКУЮ СЕНАТСКУЮ КОНТОРУ ${ }^{37}$, А ЕЕ БЫВШИЙ РУКОВОДИТЕЛЬ А.А. МАТВЕЕВ С СЕНТЯБРЯ 1725 Г. НАЧАЛ ПОСЕЩАТЬ ЗАСЕДАНИЯ СЕНАТА В САНКТ-ПЕТЕРБУРГЕ ${ }^{38}$. Я.В. БРЮС ПОСЛЕДНИЙ РАЗ ПОДПИСАЛ ПРОТОКОЛЫ 22 ДЕКАБРЯ 1725 Г. ${ }^{39}$ ТЕПЕРЬ РАССМОТРИМ СОСТАВ СЕНАТА В ПЕРЕЛОМНЫЙ ДЛЯ НЕГО ПЕРИОД (В СВЯЗИ С ОБРАЗОВАНИЕМ ВЕРХОВНОГО ТАЙНОГО СОВЕТА) - ЯНВАРЬ-МАРТ 1726 Г. (СМ. ТАБЛ. 3) ${ }^{40}$.

Таблица 3 - Участие в работе Сената (январь-март 1726 г.)

\begin{tabular}{|c|c|c|c|c|c|c|c|c|c|c|c|c|c|c|c|c|c|}
\hline $\begin{array}{c}\text { Год, } \\
\text { месяц }\end{array}$ & 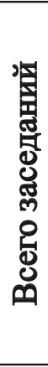 & 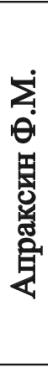 & 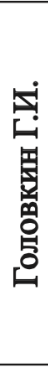 & 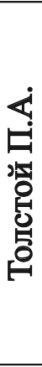 & 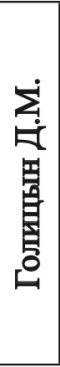 & 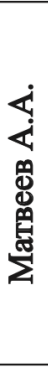 & 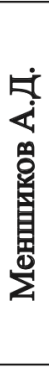 & 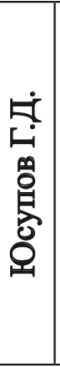 & 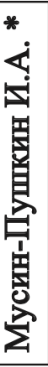 & 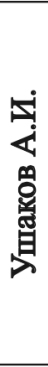 & 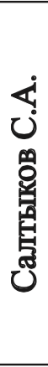 & 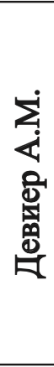 & 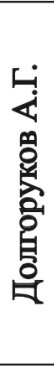 & 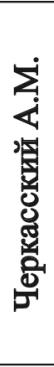 & 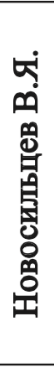 & 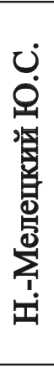 & 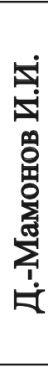 \\
\hline \multicolumn{18}{|c|}{1726 г. } \\
\hline январь & 6 & 6 & 5 & 5 & 3 & 6 & 1 & 6 & - & 6 & - & - & - & - & - & - & - \\
\hline февраль & 9 & 4 & 2 & 3 & 4 & 3 & 3 & 3 & - & 3 & 5 & 5 & 6 & 6 & - & - & 6 \\
\hline март & 18 & - & - & - & - & - & - & - & - & - & 18 & 17 & 18 & 17 & 2 & 2 & 17 \\
\hline
\end{tabular}

*И.А. Мусин-Пушкин возглавлял Сенатскую контору в Москве. Прочерк - отсутствие данных о посещении.

15 В ЯНВАРЕ 1726 Г. СЕНАТ ПОСЕЩАЛИ ГР. Ф.М. АПРАКСИН, ГР. Г.И. ГОЛОВКИН, ГР. П.А. ТОЛСТОЙ, КН. Д.М. ГОЛИЦЫН, ГР. А.А. МАТВЕЕВ, КН. А.Д. МЕНШИКОВ, КН. Г.Д. ЮСУПОВ И А.И. УШАКОВ. КАК ВИДИМ, ИНТЕНСИВНОСТЬ РАБОТЫ СЕНАТА В ЭТИ МЕСЯЦЫ БЫЛА НЕВЫСОКОЙ (ВПЛОТЬ ДО ФОРМИРОВАНИЯ НОВОГО СОСТАВА К МАРТУ 1726 Г.). МОСКОВСКУЮ КОНТОРУ СЕНАТА, КАК И РАНЕЕ, ВОЗГЛАВЛЯЛ ГР. И.А. МУСИН-ПУШКИН. В СВЯЗИ С УЧРЕЖДЕНИЕМ ВЕРХОВНОГО ТАЙНОГО СОВЕТА 8 ФЕВРАЛЯ 1726 Г. ИЗ СЕНАТА ВЫБЫЛИ ПЯТЬ ЧЕЛОВЕК: Ф.М. АПРАКСИН, Д.М. ГОЛИЦЫН, Г.И.ГОЛОВКИН, А.Д. МЕНШИКОВ, П.А. ТОЛСТОЙ ${ }^{41}$. В ТОТ ЖЕ ДЕНЬ ГР. А.А. МАТВЕЕВ БЫЛ ОПРЕДЕЛЕН РУКОВОДИТЕЛЕМ СЕНАТСКОЙ РЕВИЗИИ МОСКОВСКОЙ ГУБЕРНИИ ${ }^{42}$. ПО УКАЗУ ОТ 8 ФЕВРАЛЯ $1726 \Gamma^{43}$ В СЕНАТ БЫЛИ НАЗНАЧЕНЫ И.Ф.БУТУРЛИН ${ }^{44}$, А.М. ДЕВИЕР, И.И. ДМИТРИЕВ-МАМОНОВ, А.Г. ДОЛГОРУКОВ, С.А. САЛТЫКОВ, А.М. ЧЕРКАССКИЙ. ПЯТЕРО ИЗ ШЕСТИ СЕНАТОРОВ (КРОМЕ И.Ф.БУТУРЛИНА) ПРИСТУПИЛИ К РАБОТЕ И СТАЛИ ПОДПИСЫВАТЬ ПРОТОКОЛЫ С 17 ФЕВРАЛЯ 1726 Г. ${ }^{45}$ БУТУРЛИН НАЧАЛ ПОСЕЩАТЬ ЗАСЕДАНИЯ ЗНАЧИТЕЛЬНО ПОЗЖЕ. ЕГО ПОДПИСЕЙ ПОД СОХРАНИВШИМИСЯ СЕНАТСКИМИ ПРОТОКОЛАМИ ФЕВРАЛЯ-МАРТА 1726 Г. НЕТ, А ПО ДАННЫМ ПУБЛИКАЦИИ МАТЕРИАЛОВ 
ВЕРХОВНОГО ТАЙНОГО СОВЕТА, УЧАСТИЕ И.Ф.БУТУРЛИНА В РАБОТЕ СЕНАТА ФИКСИРУЕТСЯ ЛИШЬ В ИЮНЕ 1726 Г. ${ }^{46}$ В УКАЗЕ 8 ФЕВРАЛЯ 1726 Г. ТАКЖЕ ГОВОРИЛОСЬ О НАЗНАЧЕНИИ В СЕНАТ А.И. УШАКОВА И Г.Д. ЮСУПОВА, НО ПОСЛЕ 9 ФЕВРАЛЯ ИХ ПОДПИСИ ПОД СЕНАТСКИМИ ПРОТОКОЛАМИ УЖЕ НЕ ВСТРЕЧАЮТСЯ. ОЧЕВИДНО, РЕШЕНИЕ О НАЗНАЧЕНИИ УШАКОВА И ЮСУПОВА БЫЛО ОТМЕНЕНО ${ }^{47}$. В МАРТЕ 1726 Г. СЕНАТОРАМИ СТАЛИ В.Я. НОВОСИЛЬЦЕВ ${ }^{48}$ И Ю.С. НЕЛЕДИНСКИЙ-МЕЛЕЦКИЙ ${ }^{49}$, В МАЕ -Ф.В. НАУМОВ ${ }^{50}$. ОДНАКО УЖЕ В ИЮЛЕ 1726 Г. ИЗ СЕНАТА ВЫБЫЛ И.Ф. БУТУРЛИН. В АПРЕЛЕ 1727 Г. ПОПАЛ ПОД АРЕСТ А.М. ДЕВИЕР ${ }^{51}$, В ИЮНЕ БЫЛ НАПРАВЛЕН В МАЛОРОССИЮ Ф.В. НАУМОВ ${ }^{52}$, С ИЮЛЯ ПЕРЕСТАЛ ПОДПИСЫВАТЬ СЕНАТСКИЕ ПРОТОКОЛЫ А.Г. ДОЛГОРУКОВ, А С ОКТЯБРЯ С.А. САЛТЫКОВ ${ }^{53}$. В ТОМ ЖЕ 1727 Г. ОТ ДЕЛ ПО СТАРОСТИ ОТОШЕЛ И.А. МУСИН-ПУШКИН ${ }^{54}$. В МАЕ 1728 Г. ПОД СЛЕДСТВИЕМ ОКАЗАЛСЯ СЕНАТОР Ю.С. НЕЛЕДИНСКИЙ-МЕЛЕЦКИЙ ${ }^{5}$. ПОСЛЕДНИЕ ПРИ ПЕТРЕ ІІ НАЗНАЧЕНИЯ В СЕНАТ СОСТОЯЛИСЬ В МАЕ-СЕНТЯБРЕ 1728 Г. : ПО УКАЗУ ОТ 17 МАЯ СЕНАТОРАМИ СТАЛИ КН. М.М. МЛАДШИЙ ГОЛИЦЫН ${ }^{56}$, ГР. И.Г. ГОЛОВКИН ${ }^{57}$, А.Л. ПЛЕЩЕЕВ ${ }^{58}$, И.П. ШЕРЕМЕТЕВ ${ }^{59}$, А 2 СЕНТЯБРЯ - КН. И.Г. ДОЛГОРУКОВ ${ }^{60}$.

ЧИНОВНАЯ СТРУКТУРА СЕНАТА МЕНЯЛАСЬ В ЗАВИСИМОСТИ ОТ СТАТУСА ЭТОГО УЧРЕЖДЕНИЯ И ЕГО МЕСТА В ИЕРАРХИИ ВЛАСТИ. В 1725 Г. $83 \%$ СЕНАТОРОВ НОСИЛИ ЧИНЫ ДВУХ СТАРШИХ КЛАССОВ ТАБЕЛИ О РАНГАХ. ПОСЛЕ СОЗДАНИЯ ВЕРХОВНОГО ТАЙНОГО СОВЕТА ДОЛЯ ВЫСШИХ ЧИНОВ В СЕНАТЕ РЕЗКО УПАЛА, А В 1728-1730 ГГ. ОН УЖЕ ПОЛНОСТЬЮ СОСТОЯЛ ИЗ ТАЙНЫХ И ДЕЙСТВИТЕЛЬНЫХ СТАТСКИХ СОВЕТНИКОВ (3-4 кЛАссы).

ПРОАНАЛИЗИРУЕМ СОЦИАЛЬНУЮ СТРУКТУРУ СЕНАТА. С 1725 ДО 1730 Г. В ДОЛЖНОСТИ СЕНАТОРА ПОБЫВАЛО 26 ЧЕЛОВЕК. ПОЧТИ ВСЕ (КРОМЕ Я.В. БРЮСА И А.М. ДЕВИЕРА) БЫЛИ РУССКИМИ. В ПРАВЛЕНИЕ ПЕТРА ІІ ИНОЗЕМЦЕВ В СЕНАТЕ УЖЕ НЕ ОСТАВАЛОСЬ. ДОЛЬШЕ ОСТАЛЬНЫХ СЕНАТОРАМИ БЫЛИ И.И. ДМИТРИЕВ-МАМОНОВ, В.Я. НОВОСИЛЬЦЕВ И КН. А.М. ЧЕРКАССКИЙ (1726-1730 ГГ.). ДИНАМИКА СОСТАВА СЕНАТА ВО МНОГОМ СХОЖА С ИЗМЕНЕНИЯМИ В ВЕРХОВНОМ ТАЙНОМ СОВЕТЕ (СМ. ТАБЛ. 1,4$)$.

Таблица 4 - Состав Сената в 1724-1730 гг., \%

\begin{tabular}{|l|r|r|r|r|r|r|r|r|r|}
\hline \multicolumn{1}{|c|}{ Групша } & 1724 г. & $\mathbf{1 7 2 5}$ г. & $\mathbf{1 7 2 6}$ & $\mathbf{1 7 2 7}$ (Е) & $\mathbf{1 7 2 7}(\mathbf{I})$ & $\mathbf{1 7 2 8}$ г. & $\mathbf{1 7 2 9}$ г. & $\mathbf{1 7 3 0}$ г. & $\boldsymbol{\Delta}^{*}$ \\
\hline иноземцы & 9 & 8 & 6 & 11 & 0 & 0 & 0 & 0 & -7 \\
\hline русские, I гр. & 27 & 25 & 28 & 33 & 38 & 63 & 71 & 63 & +41 \\
\hline русские, II гр. & 45 & 42 & 28 & 11 & 13 & 0 & 0 & 13 & -28 \\
\hline русские, III гр. & 9 & 17 & 33 & 44 & 50 & 38 & 29 & 25 & +2 \\
\hline русские, IV гр. & 9 & 8 & 6 & 0 & 0 & 0 & 0 & 0 & -7 \\
\hline Итого & 100 & 100 & 100 & 100 & 100 & 100 & 100 & 100 & 0 \\
\hline в т. ч., русские I-II гр. & 73 & 67 & 56 & 44 & 50 & 63 & 71 & 75 & +12 \\
\hline
\end{tabular}

* Здесь и в таблицах 5-9 - разность между средними значениями конца (1729-1730 гг.) и начала (1725-1726 гг.) периода.

КАК ВИДИМ, ДОЛЯ АРИСТОКРАТИИ (І ГРУППА) СРЕДИ СЕНАТОРОВ ВОЗРОСЛА С 25-38 \% В 1725-1727 ГГ. ДО 63-71\% В 1728-1730 ГГ. ЧИСЛО ПРЕДСТАВИТЕЛЕЙ ДУМНЫХ ФАМИЛИЙ XVII В. (ІІ ГРУППА) СООТВЕТСТВЕННО СОКРАТИЛОСЬ С 42-11 \% ДО 0-13 \%. ДЛЯ СРАВНЕНИЯ, ПРИ ПЕТРЕ ВЕЛИКОМ (1711-1725 ГГ.) ВЫХОДЦАМИ ИЗ І ГРУППЫ ЯВЛЯЛИСЬ $30 \%$ СЕНАТОРОВ, ИЗ ІІ ГРУППЫ - $43 \%{ }^{61}$. В ПЕРВЫЙ ГОД РАБОТЫ СЕНАТА ПРИ ЕКАТЕРИНЕ 
СИТУАЦИЯ ОСТАВАЛАСЬ ТОЙ ЖЕ И ЛИШЬ В ДАЛЬНЕЙШЕМ ИЗМЕНИЛАСЬ В ПОЛЬЗУ ЗНАТИ (ОСОБЕННО ПРИ ПЕТРЕ ІІ). ВАЖНЕЙШИМ ОТЛИЧИЕМ ОТ ВЕРХОВНОГО ТАЙНОГО СОВЕТА БЫЛО ТО, ЧТО В СЕНАТ В 1725-1730 ГГ. АКТИВНО ЖАЛОВАЛИСЬ ПРЕДСТАВИТЕЛИ НЕДУМНОГО ДВОРЯНСТВА (III ГРУППА): И.И. ДМИТРИЕВ-МАМОНОВ, Ф.В.НАУМОВ, Ю.С. НЕЛЕДИНСКИЙ-МЕЛЕЦКИЙ, В.Я. НОВОСИЛЬЦЕВ, А.И. УШАКОВ, КН. Г.Д. ЮСУПОВ. УДЕЛЬНЫЙ ВЕС МОСКОВСКОГО ДВОРЯНСТВА В 1725-1730 ГГ. КОЛЕБАЛСЯ ОТ 17 ДО 50 \%. В 1726-1727 ГГ. ВЫХОДЦЫ ИЗ ЭТОГО СЛОЯ БЫЛИ В СЕНАТЕ ПЕРВЫМИ, А В 1728-1730 ГГ. ВТОРЫМИ ПО чИСЛЕННОСТИ.

ТАКЖЕ СЛЕДУЕТ ОБРАТИТЬ ПРИСТАЛЬНОЕ ВНИМАНИЕ НА ИЗМЕНЕНИЕ ОБЩИХ ПРИНЦИПОВ ФОРМИРОВАНИЯ ВЫСШИХ ОРГАНОВ ВЛАСТИ (СЕНАТ - ПРИ ПЕТРЕ I, ВЕРХОВНЫЙ ТАЙНЫЙ СОВЕТ И СЕНАТ - ПРИ ЕКАТЕРИНЕ I И ПЕТРЕ II). СУДЯ ПО ТОМУ, ЧТО ПЕТР ВЕЛИКИЙ СТАРАЛСЯ НЕ НАЗНАЧАТЬ В СЕНАТ НЕСКОЛЬКИХ ЧЕЛОВЕК ИЗ ОДНОЙ ФАМИЛИИ ОДНОВРЕМЕННО, ОН СЧИТАЛ, ЧТО ЭТО ОПАСНО ДЛЯ БАЛАНСА СИЛ ВНУТРИ ЭЛИТЫ ${ }^{62}$. ТАК, ГР. Ф.М. АПРАКСИН НАЧАЛ ПРИСУТСТВОВАТЬ НА ЗАСЕДАНИЯХ С 1718 Г., А ЕГО РОДНОЙ БРАТ ГР. П.М. АПРАКСИН, ЗАМЕШАННЫЙ В ДЕЛЕ ЦАРЕВИЧА АЛЕКСЕЯ, ВЫБЫЛ ИЗ СЕНАТА В ТОМ ЖЕ ГОДУ. КН. Д.М. ГОЛИЦЫН ПОЛУЧИЛ ДОЛЖНОСТЬ СЕНАТОРА В 1718 Г., УЖЕ ПОСЛЕ ТОГО КАК ЕГО ДВОЮРОДНЫЙ БРАТ П.А. ГОЛИЦЫН В 1713 Г. БЫЛ ПЕРЕВЕДЕН НА ПОСТ РИЖСКОГО ГУБЕРНАТОРА. ЕДИНСТВЕННЫМ ИСКЛЮЧЕНИЕМ ИЗ ЭТОГО ПРАВИЛА СТАЛИ НАЗНАЧЕНИЯ 22 ФЕВРАЛЯ 1711 Г. КН. М.В. ДОЛГОРУКОВА (ЛИШЕН ДОЛЖНОСТИ В 1718 Г.) И 18 АВГУСТА 1711 Г. КН. Я.Ф. ДОЛГОРУКОВА (УМЕР В ИЮНЕ 1720 Г.). ПОСЛЕ 1718 Г. ПОДОБНЫХ СЛУЧАЕВ УЖЕ НЕ НАБЛЮДАЛОСЬ. ПО ВСЕЙ ВИДИМОСТИ, ЭТО БЫЛО СВЯЗАНО С РЕЗУЛЬТАТАМИ СЛЕДСТВИЯ ПО ДЕЛУ АЛЕКСЕЯ ПЕТРОВИЧА, ВСКРЫВШЕГО ЗНАЧИТЕЛЬНЫЕ МАСШТАБЫ СОЧУВСТВИЯ И ПОДДЕРЖКИ ЦАРЕВИЧУ СО СТОРОНЫ ЗНАТИ (В ТОМ ЧИСЛЕ, КЛАНА ДОЛГОРУКОВЫХ $)^{63}$. В ЭТОМ ЖЕ ГОДУ В СЕНАТ ВОШЛИ САМЫЕ ВЛИЯТЕЛЬНЫЕ ЛИЦА ИЗ ОКРУЖЕНИЯ ПЕТРА І (КН. А.Д. МЕНШИКОВ, ГР. Ф.М. АПРАКСИН, ГР. Г.И. ГОЛОВКИН) И СЕНАТ НЕ ТОЛЬКО ФОРМАЛЬНО, НО И ФАКТИЧЕСКИ ПРЕВРАТИЛСЯ В ВЫСШЕЕ ГОСУДАРСТВЕННОЕ УЧРЕЖДЕНИЕ. С ЭТИХ ПОР ДОЛГОРУКОВЫ НАЗНАЧАЛИСЬ В СЕНАТ ТОЛЬКО ПО ОДНОМУ. НАПРИМЕР, КН. Г.Ф. ДОЛГОРУКОВ СТАЛ СЕНАТОРОМ В 1721 Г. (УЖЕ ПОСЛЕ СМЕРТИ СТАРШЕГО БРАТА ЯКОВА ФЕДОРОВИЧА), А КН. В.Л. ДОЛГОРУКОВ - ТОЛЬКО 10 АВГУСТА 1723 Г. (ЗА НЕСКОЛЬКО ДНЕЙ ДО КОНЧИНЫ СВОЕГО ДЯДИ ГРИГОРИЯ ФЕДОРОВИЧА 15 АВГУСТА 1723 Г. $)^{64}$. ЕКАТЕРИНА І ПРОДОЛЖИЛА ЭТУ ПОЛИТИКУ: КН. А.Г. ДОЛГОРУКОВ БЫЛ НАЗНАЧЕН В СЕНАТ 8 ФЕВРАЛЯ 1726 Г., ТОЛЬКО ПОСЛЕ ТОГО, КАК В ИЮНЕ 1725 Г. ИЗ НЕГО ВЫБЫЛ ЕГО ДВОЮРОДНЫЙ БРАТ В.Л. ДОЛГОРУКОВ. ТАКИМ ОБРАЗОМ, ДО ПЕТРА ІІ ОДНОВРЕМЕННОЕ ПРИСУТСТВИЕ ЕДИНОРОДЦЕВ В ВЫСШИХ ОРГАНАХ ВЛАСТИ ДОПУСКАЛОСЬ ЛИШЬ ОДНАЖДЫ И МОЖЕТ РАССМАТРИВАТЬСЯ КАК ИСКЛЮЧИТЕЛЬНОЕ ЯВЛЕНИЕ. В 1728 Г. ЭТОТ НЕГЛАСНЫЙ ПРИНЦИП ДВУХ ПРЕДШЕСТВУЮЩИХ ЦАРСТВОВАНИЙ БЫЛ ГРУБО НАРУШЕН : В СОСТАВ ВЕРХОВНОГО ТАЙНОГО СОВЕТА ВОШЛИ КН. А.Г. И В.Л. ДОЛГОРУКОВЫ, А В СЕНАТ - РОДНОЙ БРАТ ПЕРВОГО И.Г. ДОЛГОРУКОВ. В НАЧАЛЕ 1730 Г. СОВЕТ ПОПОЛНИЛСЯ ЕЩЕ ОДНИМ ПРЕДСТАВИТЕЛЕМ ЭТОЙ ФАМИЛИИ ФЕЛЬДМАРШАЛОМ КН. В.В. ДОЛГОРУКОВЫМ. В ТОМ ЖЕ 1728 Г. СЕНАТОРОМ БЫЛ НАЗНАЧЕН КН. М.М. МЛАДШИЙ ГОЛИЦЫН (ОДНОВРЕМЕННО В СОСТАВЕ СОВЕТА УЖЕ ЗАСЕДАЛ ЕГО РОДНОЙ БРАТ КН. Д.М. ГОЛИЦЫН), А В НАЧАЛЕ 1730 Г. « ВЕРХОВНИКОМ» СТАЛ ЕЩЕ ОДИН БРАТ - ФЕЛЬДМАРШАЛ КН. М.М. СТАРШИЙ ГОЛИЦЫН. ТРЕТЬЕЙ ФАМИЛИЕЙ, НА КОТОРУЮ ПРИ ПЕТРЕ II РАСПРОСТРАНИЛИСЬ ПОДОБНЫЕ « КАДРОВЫЕ ПРИВИЛЕГИИ», СТАЛИ ГР. ГОЛОВКИНЫ. ПОМИМО КАНЦЛЕРА ГР. Г.И. ГОЛОВКИНА, СОСТОЯВШЕГО В СОВЕТЕ С 
МОМЕНТА ОБРАЗОВАНИЯ, В МАЕ 1728 Г. СЕНАТОРОМ БЫЛ НАЗНАЧЕН ЕГО СЫН ГР. И.Г. ГОЛОВКИН (НАЧАЛ ПРИСУТСТВОВАТЬ С ЯНВАРЯ 1730 Г.). В ИТОГЕ, К ФЕВРАЛЮ 1730 Г. В ВЕРХОВНОМ ТАЙНОМ СОВЕТЕ И СЕНАТЕ ЗАСЕДАЛО ЧЕТВЕРО ДОЛГОРУКОВЫХ, ТРОЕ ГОЛИЦЫНЫХ И ДВОЕ ГОЛОВКИНЫХ. «КЛАНОВОСТЬ» ПРИ ЗАМЕЩЕНИИ ВЫСШИХ ГОСУДАРСТВЕННЫХ ДОЛЖНОСТЕЙ ПРЕВРАТИЛАСЬ ИЗ ИСКЛЮЧЕНИЯ В РАСПРОСТРАНЕННОЕ ЯВЛЕНИЕ. ИМЕННО ПО ЭТОЙ ПРИЧИНЕ НЕОБХОДИМОСТЬ ОГРАНИЧЕНИЯ ЧИСЛА ЕДИНОРОДЦЕВ В СОВЕТЕ И СЕНАТЕ ТАК ШИРОКО ОБСУЖДАЛАСЬ В «ШЛЯХЕТСКИХ ПРОЕКТАХ» НАЧАЛА 1730 Г. ЧРЕЗМЕРНОЕ УСИЛЕНИЕ ОТДЕЛЬНЫХ ФАМИЛИЙ УГРОЖАЛО ПРЕВРАТИТЬ МОНАРХИЮ В «ОЛИГАРХИЧЕСКОЕ ПРАВЛЕНИЕ» И НАРУШАЛО СТАБИЛЬНОСТЬ ВСЕЙ ВЛАСТНОЙ ПИРАМИДЫ.

ПЕРЕЙДЕМ К АППАРАТУ ЦЕНТРАЛЬНОГО УПРАВЛЕНИЯ, К КОТОРОМУ ОТНОСИЛИСЬ КОЛЛЕГИИ, А ТАКЖЕ ЦЕЛЫЙ РЯД КАНЦЕЛЯРИЙ, КОНТОР И ПРИКАЗОВ, ПОДЧИНЕННЫХ ВЕРХОВНОМУ ТАЙНОМУ СОВЕТУ, СЕНАТУ ИЛИ НЕПОСРЕДСТВЕННО МОНАРХУ ${ }^{65}$. НА ПОСТУ РУКОВОДИТЕЛЯ КОЛЛЕГИИ (ПРЕЗИДЕНТА ИЛИ ЛИЦА ЕГО ЗАМЕНЯЮЩЕГО) В 1725-1730 ГГ. В ОБЩЕЙ СЛОЖНОСТИ ПОБЫВАЛО 26 ЧЕЛОВЕК. БОЛЬШИНСТВО ИЗ НИХ ЯВЛЯЛИСЬ РУССКИМИ (22 ЧЕЛОВЕКА ; ПО ЕЖЕГОДНЫМ ДАННЫМ - 75-100 \% ${ }^{66}$. ИНОЗЕМЦЕВ БЫЛО ЛИШЬ ЧЕТВЕРО (0-25\%): ПРЕЗИДЕНТ БЕРГ-КОЛЛЕГИИ ГР. Я.В.БРЮС, ПЕРВЫЙ ЧЛЕН ВОЕННОЙ КОЛЛЕГИИ ГР. Б.-Х. МИНИХ, ВИЦЕ-ПРЕЗИДЕНТЫ АДМИРАЛТЕЙСКОЙ КОЛЛЕГИИ П.И. СИВЕРС - И КОММЕРЦ-КОЛЛЕГИИ - Г. ФОН ФИК. ИЗ НИХ ЧИН ПРЕЗИДЕНТА НОСИЛ ТОЛЬКО Я.В.БРЮС, ОСТАЛЬНЫЕ ИСПОЛНЯЛИ ОБЯЗАННОСТИ ГЛАВЫ КОЛЛЕГИИ. ПОСТ ПРЕЗИДЕНТА (ОБЫЧНО ЗАМЕЩАЕМЫЙ РУССКИМИ) В ВОЕННОЙ, АДМИРАЛТЕЙСКОЙ И КОММЕРЦ-КОЛЛЕГИЯХ В 1728-1730 ГГ. ОСТАВАЛСЯ ВАКАНТНЫМ. ЗА СЧЕТ ЭТОГО, ДОЛЯ ИНОЗЕМЦЕВ СРЕДИ ВЫСШЕГО РУКОВОДСТВА КОЛЛЕГИЙ ВЫРОСЛА ДО 20-25 \%. ПРИ НАЗНАЧЕНИИ ВИЦЕ-ПРЕЗИДЕНТОВ ПРЕДПОЧТЕНИЕ ОТДАВАЛОСЬ ИНОЗЕМЦАМ (7 ЧЕЛОВЕК; ПО ЕЖЕГОДНЫМ ДАННЫМ - 50-71\%)67. РУССКИХ ВИЦЕ-ПРЕЗИДЕНТОВ ЗА 1725-1730 ГГ. БЫЛО ПЯТЕРО (29-50\%): А.К. ЗЫБИН (БЕРГ-КОЛЛЕГИЯ), Ф.С. МАНУКОВ (ВОТЧИННАЯ), А.П. АРСЕНЬЕВ (МАЛОРОССИЙСКАЯ), А.Ю.БИБИКОВ (МАНУФАКТУР И РЕВИЗИОН $\left.{ }^{68}\right)$, Г.Т. ЕРГОЛЬСКИЙ (ЮСТИЦ $\left.{ }^{69}\right)$. ТАКИМ ОБРАЗОМ, В ИЗУЧАЕМЫЙ ПЕРИОД СОХРАНЯЛАСЬ ПЕТРОВСКАЯ ТРАДИЦИЯ ФОРМИРОВАНИЯ КОЛЛЕЖСКОГО РУКОВОДСТВА ПО НАЦИОНАЛЬНОМУ ПРИЗНАКУ.

ОБРАТИМ ВНИМАНИЕ НА ДИНАМИКУ СОЦИАЛЬНОЙ СТРУКТУРЫ ВЫСШИХ КОЛЛЕЖСКИХ ЧИНОВ (ТАБЛ. 5-6).

Таблица 5 - Президенты и руководители коллегий, 1725-1730 гг., \%

\begin{tabular}{|l|l|l|l|l|l|l|l|l|}
\hline ГРУППА & 1725 г. & 1726 г. & $1727($ Е) & $1727(П)$ & 1728 г. & 1729 г. & 1730 г. & $\Delta$ \\
\hline ИнОЗЕМцЫ & 7 & 7 & 0 & 8 & 23 & 20 & 25 & +16 \\
\hline РУсскИЕ, І ГР. & 27 & 13 & 14 & 15 & 8 & 10 & 13 & -9 \\
\hline РУсскИЕ, ІІ гР. & 47 & 40 & 36 & 23 & 23 & 20 & 25 & -21 \\
\hline РУсскИЕ, ІІІ гР. & 7 & 27 & 36 & 31 & 31 & 40 & 25 & +16 \\
\hline РУсскИЕ, ІУ гР. & 13 & 13 & 14 & 23 & 15 & 10 & 13 & -2 \\
\hline
\end{tabular}




\begin{tabular}{|l|l|l|l|l|l|l|l|l|}
\hline итого & 100 & 100 & 100 & 100 & 100 & 100 & 100 & 0 \\
\hline В Т. Ч., РУсСКИЕ І-ІІ гР. & 73 & 53 & 50 & 38 & 31 & 30 & 38 & -30 \\
\hline
\end{tabular}

Таблица 6 - Вице-президенты коллегий, 1725-1730 гг., \%

\begin{tabular}{|l|l|l|l|l|l|l|l|l|}
\hline гРУППА & 1725 г. & 1726 г. & $1727($ Е) & $1727($ п) & 1728 г. & 1729 г. & 1730 г. & $\Delta$ \\
\hline ИнозЕмцЫ & 71 & 56 & 50 & 55 & 71 & 71 & 71 & +8 \\
\hline РУсскиЕ, І гР. & 0 & 0 & 0 & 0 & 0 & 0 & 0 & 0 \\
\hline РУсскиЕ, ІІ гР. & 0 & 0 & 0 & 0 & 0 & 0 & 0 & 0 \\
\hline РУсскиЕ, ІІІ гР. & 29 & 44 & 50 & 45 & 29 & 29 & 29 & -8 \\
\hline РУсскиЕ, ІУ гР. & 0 & 0 & 0 & 0 & 0 & 0 & 0 & 0 \\
\hline Итого & 100 & 100 & 100 & 100 & 100 & 100 & 100 & 0 \\
\hline в Т. Ч., РУсскиЕ І-ІІ гР. & 0 & 0 & 0 & 0 & 0 & 0 & 0 & 0 \\
\hline
\end{tabular}

СРЕДИ РУКОВОДИТЕЛЕЙ КОЛЛЕГИЙ ДОЛЯ ВЫХОДЦЕВ ИЗ ДУМНЫХ ФАМИЛИЙ (I И ІІ ГРУППЫ) СНИзИлАсь С 73-53 \% в 1725-1726 Гг. до 30-38 \% в 1729-1730 гг. в основном ЭТО ПРОИЗОШЛО ЗА СЧЕТ УМЕНЬШЕНИЯ ЧИСЛЕННОСТИ ДУМНОГО ДВОРЯНСТВА XVII В. (II ГРУППА) С 47-40 \% ДО 20-25\%. УДЕЛЬНЫЙ ВЕС МОСКОВСКОГО ДВОРЯНСТВА (ІІІ ГРУППА), НАПРОТИВ, ВЫРОС С 7-27\% ДО 40-25\%. СОСТАВ РУССКИХ ВИЦЕ-ПРЕЗИДЕНТОВ БЫЛ ИНЫМ: ВСЕ ОНИ ПРОИСХОДИЛИ ИЗ СРЕДЫ МОСКОВСКИХ ДВОРЯН (ІІІ ГРУППА). ПРЕДСТАВИТЕЛИ ДУМНЫХ ФАМИЛИЙ XVI-XVII ВВ. (I-II ГРУППА) НА ЭТОТ ПОСТ НЕ НАЗНАЧАЛИСЬ ВОВСЕ. РУКОВОДИТЕЛИ КОЛЛЕГИЙ ЧАЩЕ ВСЕГО НОСИЛИ ЧИНЫ ЧЕТВЕРТОГО КЛАССА ТАБЕЛИ О РАНГАХ (38-71 \%), А ВИЦЕ-ПРЕЗИДЕНТЫ - ПЯТОГО (57-80 \% ) .

ЧАСТЬ ЦЕНТРАЛЬНЫХ УЧРЕЖДЕНИЙ (ДОИМОЧНАЯ, ПРЕОБРАЖЕНСКАЯ, ТАЙНАЯ, ГЛАВНАЯ ДВОРЦОВАЯ КАНЦЕЛЯРИИ, МОНЕТНАЯ, РАСКОЛЬНИЧЕСКАЯ КОНТОРЫ И Т.Д.) НЕ ИМЕЛИ СТАТУСА КОЛЛЕГИЙ. СОСТАВ ВЫСШЕГО РУКОВОДСТВА, КАК И В КОЛЛЕГИЯХ, ЗДЕСЬ БЫЛ В ОСНОВНОМ РУССКИМ (77-87 \%). ЕЩЕ ОДНОЙ ОБЩЕЙ ЧЕРТОЙ БЫЛО ТО, ЧТО ГЛАВЫ ЭТИХ ОРГАНОВ ВЛАСТИ ЧАЩЕ ВСЕГО НОСИЛИ ЧИНЫ ЧЕТВЕРТОГО КЛАССА ТАБЕЛИ (В 1725-1727 ГГ. - 29-40\%, В 1728-1730 ГГ. - 55-60\%). ОДНАКО НА ЭТОМ сХОДСТВО ЗАКАНЧИВАЛОСЬ (СМ. ТАБЛ. 7).

Таблица 7 - Руководство других центральных учреждений, 1725-1730 гг., \%

\begin{tabular}{|l|l|l|l|l|l|l|l|l|}
\hline ГРУППА & 1725 г. & 1726 г. & $1727(\mathrm{E})$ & $1727(п)$ & 1728 г. & 1729 г. & 1730 г. & $\Delta$ \\
\hline ИнОЗЕмцЫ & 23 & 21 & 23 & 13 & 18 & 18 & 20 & -3 \\
\hline
\end{tabular}




\begin{tabular}{|l|l|l|l|l|l|l|l|l|}
\hline РУсскИЕ, І ГР. & 15 & 21 & 31 & 33 & 36 & 36 & 30 & +15 \\
\hline РУсскИЕ, ІІ ГР. & 23 & 21 & 15 & 20 & 18 & 18 & 20 & -3 \\
\hline РУсскИЕ, ІІІ гР. & 23 & 21 & 23 & 20 & 27 & 27 & 30 & +6 \\
\hline РУсскИЕ, ІУ гР. & 15 & 14 & 8 & 13 & 0 & 0 & 0 & -15 \\
\hline ИТогО & 100 & 100 & 100 & 100 & 100 & 100 & 100 & 0 \\
\hline В т. Ч., РУсскиЕ І-ІІ гР. & 38 & 43 & 46 & 53 & 55 & 55 & 50 & +12 \\
\hline
\end{tabular}

В УЧРЕЖДЕНИЯХ, НЕ ОБЛАДАВШИХ КОЛЛЕЖСКИМ СТАТУСОМ, ПОЗИЦИИ МОСКОВСКОЙ ЭЛИТЫ СТАЛИ ПРОЧНЕЕ. ПРЕДСТАВИТЕЛЕЙ І-ІІ ГРУПП ЗДЕСЬ НАСЧИТЫВАЛОСЬ 38-43 \% В 1725-1726 ГГ., А В 1729-1730 ГГ. - 55-50\%. ЭТО ОБЪЯСНЯЛОСЬ РОСТОМ ЧИСЛЕННОСТИ ЗНАТИ (І ГРУППА) С 15-21\% ДО 36-30\%. АРИСТОКРАТЫ ВОЗГЛАВЛЯЛИ ГЛАВНЫЙ МАГИСТРАТ (КН. А.Г. ДОЛГОРУКОВ), МАСТЕРСКУЮ И ОРУЖЕЙНУЮ ПАЛАТУ (КН. В.Ю. ОДОЕВСКИЙ), МОНЕТНУЮ КОНТОРУ (А.Л. ПЛЕЩЕЕВ), ДОИМОЧНУЮ (И.Н. ПЛЕЩЕЕВ) И ПРЕОБРАЖЕНСКУЮ (КН. И.Ф. РОМОДАНОВСКИЙ) КАНЦЕЛЯРИИ.

ТЕПЕРЬ РАССМОТРИМ СОСТАВ ГУБЕРНСКОГО РУКОВОДСТВА 1725-1730 ГГ. В ОБЩЕЙ СЛОЖНОСТИ ЗДЕСЬ СЛУЖИЛО 48 ЧЕЛОВЕК, СРЕДИ НИХ 34 ГУБЕРНАТОРА (ВКЛЮЧАЯ ЛИЦ ВРЕМЕННО УПРАВЛЯВШИХ ГУБЕРНИЯМИ) ${ }^{70}$ И 21 ВИЦЕ-ГУБЕРНАТОР ${ }^{71}$ (СМ. ТАБЛ. 8-9).

Таблица 8 - Губернаторы, генерал-губернаторы, главы губерний, 1725-1730 гг., \%

\begin{tabular}{|l|l|l|l|l|l|l|l|l|}
\hline ГРУППА & 1725 г. & 1726 г. & $1727($ Е) & $1727($ п) & 1728 г. & 1729 г. & 1730 г. & $\Delta$ \\
\hline ИнОзЕМЦЫ & 0 & 11 & 14 & 20 & 21 & 27 & 31 & +23 \\
\hline РУсскИЕ, І ГР. & 31 & 22 & 24 & 20 & 26 & 27 & 23 & -2 \\
\hline РУсскИЕ, ІІ ГР. & 46 & 33 & 29 & 25 & 21 & 0 & 0 & -40 \\
\hline РУсскИЕ, ІІІ ГР. & 15 & 28 & 29 & 30 & 32 & 47 & 46 & +25 \\
\hline РУсскИЕ, ІУ гР. & 8 & 6 & 5 & 5 & 0 & 0 & 0 & -7 \\
\hline ИТОгО & 100 & 100 & 100 & 100 & 100 & 100 & 100 & 0 \\
\hline В Т. Ч., РУсскИЕ І-ІІ гР. & 77 & 56 & 52 & 45 & 47 & 27 & 23 & -41 \\
\hline
\end{tabular}

Таблица 9 - Вице-губернаторы, 1725-1730 гг., \%

\begin{tabular}{|l|l|l|l|l|l|l|l|l|}
\hline ГРУППА & 1725 г. & 1726 г. & $1727($ Е) & $1727($ П) & 1728 г. & 1729 г. & 1730 г. & $\Delta$ \\
\hline ИнОЗЕМЦЫ & 11 & 18 & 23 & 29 & 27 & 36 & 36 & +22 \\
\hline РУсСКИЕ, І ГР. & 0 & 18 & 15 & 14 & 7 & 9 & 9 & 0 \\
\hline
\end{tabular}




\begin{tabular}{|l|l|l|l|l|l|l|l|l|}
\hline РУсСКИЕ, ІІ ГР. & 33 & 27 & 15 & 14 & 20 & 18 & 18 & -12 \\
\hline РУсСКИЕ, ІІІ ГР. & 56 & 36 & 46 & 43 & 47 & 36 & 36 & -10 \\
\hline РУсСКИЕ, IV ГР. & 0 & 0 & 0 & 0 & 0 & 0 & 0 & 0 \\
\hline ИТОГО & 100 & 100 & 100 & 100 & 100 & 100 & 100 & 0 \\
\hline В Т. Ч., РУССКИЕ І-ІІ ГР. & 33 & 45 & 31 & 29 & 27 & 27 & 27 & -12 \\
\hline
\end{tabular}

КАК И ПРИ ПЕТРЕ ВЕЛИКОМ, ЗДЕСЬ ПРЕОБЛАДАЛИ РУССКИЕ. СРЕДИ ГУБЕРНАТОРОВ И ЛИЦ УПРАВЛЯВШИХ ГУБЕРНИЯМИ ДОЛЯ РУССКИХ СОСТАВЛЯЛА 69-100\%, А СРЕДИ ВИЦЕ-ГУБЕРНАТОРОВ - 64-89\%. ВМЕСТЕ С ТЕМ, ЗА ГОДЫ ПРАВЛЕНИЯ ЕКАТЕРИНЫ І И ПЕТРА ІІ ЧИСЛО ИНОЗЕМЦЕВ УВЕЛИЧИЛОСЬ С 0-14\% ДО 20-31\% (ГУБЕРНАТОРЫ) И С 11-23 \% ДО 27-36 \% (ВИЦЕ-ГУБЕРНАТОРЫ). ЕСЛИ ПРИ ПЕТРЕ I НА ВЫСШИХ ГУБЕРНСКИХ ПОСТАХ СЛУЖИЛ ОДИН ИНОЗЕМЕЦ (РЕВЕЛЬСКИЙ ВИЦЕ-ГУБЕРНАТОР БАР. ФРИДРИХ ФОН ЛЕВЕН), ТО В 1725-1730 ГГ. - УЖЕ ДЕВЯТЬ ЧЕЛОВЕК. ИНОЗЕМЦЫ НАЗНАЧАЛИСЬ ТОЛЬКО В ЗАПАДНЫЕ ПРИГРАНИЧНЫЕ ГУБЕРНИИ : ПЕТЕРБУРГСКУЮ (Б.-Х. МИНИХ, Я.-К. САПЕГА), РЕВЕЛЬСКУЮ (В.В. ДЕЛЬДЕН, Ф. ЛЕВЕН), РИЖСКУЮ (Г.-И.БОН, П.П. ЛАССИ, Ф.Н.БАЛК), КИЕВСКУЮ (Л.Л. ШТОК), СМОЛЕНСКУЮ (И.Я. ДЮПРЕ). ВСЕ ОНИ БЫЛИ ГЕНЕРАЛАМИ И ДЛИТЕЛЬНОЕ ВРЕМЯ НАХОДИЛИСЬ НА АРМЕЙСКОЙ СЛУЖБЕ ${ }^{72}$. ИСКЛЮЧЕНИЕМ ЯВЛЯЛСЯ САПЕГА, ЧЬИ СКРОМНЫЕ ВОЕННЫЕ ЗАСЛУГИ БЫЛИ МАЛО СОПОСТАВИМЫ С ПОЛУЧЕННЫМ ФЕЛЬДМАРШАЛЬСКИМ ЧИНОМ ${ }^{73}$.

ЕЩЕ ОДНОЙ ВАЖНОЙ ТЕНДЕНЦИЕЙ СТАЛО УКРЕПЛЕНИЕ ПОЗИЦИЙ МОСКОВСКОГО НЕДУМНОГО ДВОРЯНСТВА (ІІІ ГРУППА) СРЕДИ ГУБЕРНАТОРОВ. ЗА ПЯТЬ ЛЕТ ДОЛЯ ЭТОЙ ГРУППЫ ВЫРОСЛА С 15-28 \% ДО 47-46\%. СООТВЕТСТВЕННО УМЕНЬШИЛАСЬ ЧИСЛЕННОСТЬ ТРАДИЦИОННОЙ МОСКОВСКОЙ ЭЛИТЫ (I-ІІ ГРУППЫ) - С 77-56\% дО 27-23\%. ПРЕДСТАВИТЕЛИ ДУМНЫХ ФАМИЛИЙ XVII В. К КОНЦУ ПЕРИОДА ПОЛНОСТЬЮ ИСЧЕЗЛИ ИЗ ЧИСЛА ГУБЕРНАТОРОВ : В 1725-1726 ГГ. ИХ БЫЛО 46-33\%, А В 1729-1730 ГГ. - УЖЕ НИ ОДНОГО. УДЕЛЬНЫЙ ВЕС АРИСТОКРАТИИ ОСТАЛСЯ ТЕМ ЖЕ - ОКОЛО $1 / 4$. СОЦИАЛЬНАЯ СТРУКТУРА ВИЦЕ-ГУБЕРНАТОРСКОГО КОРПУСА В 1725-1730 ГГ. ПРЕТЕРПЕЛА МЕНЕЕ ЗНАЧИТЕЛЬНЫЕ ИЗМЕНЕНИЯ (СМ. ТАБЛ. 9).

ТЕПЕРЬ ПОПЫТАЕМСЯ ПРЕДСТАВИТЬ ОБЩУЮ КАРТИНУ ТЕХ ПЕРЕМЕН, КОТОРЫЕ ПРОИЗОШЛИ В АДМИНИСТРАТИВНЫХ СТРУКТУРАХ В ТЕЧЕНИЕ 1725-1730 ГГ. ТАБЛИЦЫ 10-12 СОДЕРЖАТ СРЕДНИЕ ПОКАЗАТЕЛИ УДЕЛЬНОГО ВЕСА ПЯТИ ОСНОВНЫХ СТРАТ ПРАВЯЩЕГО СЛОЯ (ИНОЗЕМЦЫ, РУССКИЕ I-IV ГРУППЫ) В 1725-1726 И 1729-1730 ГГ. НА ОСНОВЕ ЭТИХ ДАННЫХ БЫЛИ РАССЧИТАНЫ ИНДЕКСЫ ДИНАМИКИ (ТАБЛИЦА 12). ОНИ ДЕМОНСТРИРУЮТ, НАСКОЛЬКО ВЫРОСЛА ИЛИ СОКРАТИЛАСЬ ДОЛЯ ПРЕДСТАВИТЕЛЕЙ КАЖДОЙ СТРАТЫ В СОСТАВЕ ВЫСШИХ УЧРЕЖДЕНИЙ, РУКОВОДСТВЕ ЦЕНТРАЛЬНОГО И МЕСТНОГО УПРАВЛЕНИЯ. В ПОСЛЕДНЕМ СТОЛБЦЕ ТАБЛИЦ 10-11 УКАЗАНЫ КОЭФФИЦИЕНТЫ ВАРИАЦИИ (V). ОНИ ПОЗВОЛЯЮТ ОЦЕНИТЬ СТЕПЕНЬ СОЦИАЛЬНОЙ «ОДНОРОДНОСТИ» СОСТАВА ТЕХ ИЛИ ИНЫХ УЧРЕЖДЕНИЙ, А ТАКЖЕ УВИДЕТЬ НАПРАВЛЕННОСТЬ ИЗМЕНЕНИЙ (СМ. ТАБЛ. 12). 
Таблица 10 - Средние показатели удельного веса социальных групп в 1725-1726 гг., \%

\begin{tabular}{|l|r|r|r|r|r|r|}
\hline \multirow{2}{*}{\multicolumn{1}{|c|}{ Учреждение / группа }} & \multirow{2}{*}{ иноземщы } & \multicolumn{4}{c|}{ русские } & \multirow{2}{*}{ V* } \\
\cline { 3 - 6 } & & I гр. & II гр. & III гр. & IV гр. & \\
\hline ВТС & 28,6 & 14,3 & 42,9 & 0,0 & 14,3 & 73 \\
\hline Сенат & 6,9 & 26,4 & 34,7 & 25,0 & 6,9 & 56 \\
\hline коллегии, президенты & 6,7 & 20,0 & 43,3 & 16,7 & 13,3 & 62 \\
\hline коллегии, вице-президенты & $\mathbf{6 3 , 5}$ & 0,0 & 0,0 & 36,5 & 0,0 & 130 \\
\hline другие центральные учреждения & 22,3 & 18,4 & 22,3 & 22,3 & 14,8 & 15 \\
\hline губернаторы & 5,6 & 26,5 & 39,7 & 21,6 & 6,6 & 64 \\
\hline вице-губернаторы & 14,6 & 9,1 & 30,3 & 46,0 & 0,0 & 81 \\
\hline
\end{tabular}

Прим. : заливкой выделены показатели выше 25 \%, заливкой и полужирным начертанием выше $50 \%$.

* V - коэффициент вариации (в процентах)

Таблица 11 - Средние показатели удельного веса социальных групп в 1729-1730 гг., \%

\begin{tabular}{|c|c|c|c|c|c|c|}
\hline \multirow{2}{*}{ Учреждение / группа } & \multirow{2}{*}{ иноземщы } & \multicolumn{4}{|c|}{ русские } & \multirow{2}{*}{$\mathrm{V}^{*}$} \\
\hline & & I гр. & II гр. & III гр. & IV гр. & \\
\hline BTC & 17,1 & 65,7 & 17,1 & 0,0 & 0,0 & 121 \\
\hline Сенат & 0,0 & 67,0 & 6,3 & 26,8 & 0,0 & 127 \\
\hline коллегии, президенты & 22,5 & 11,3 & 22,5 & 32,5 & 11,3 & 40 \\
\hline коллегии, вице-президенты & 71,4 & 0,0 & 0,0 & 28,6 & 0,0 & 140 \\
\hline другие центральные учреждения & 19,1 & 33,2 & 19,1 & 28,6 & 0,0 & 57 \\
\hline губернаторы & 28,7 & 24,9 & 0,0 & 46,4 & 0,0 & 89 \\
\hline вице-губернаторы & 36,4 & 9,1 & 18,2 & 36,4 & 0,0 & 73 \\
\hline
\end{tabular}

Прим. : заливкой выделены показатели выше 25 \%, заливкой и полужирным начертанием выше $50 \%$.

* V - коэффициент вариации (в процентах).

Таблица 12 - Динамика по социальным группам, 1725-1730 гг., \%

\begin{tabular}{|c|c|c|c|c|c|c|}
\hline \multirow{2}{*}{ Упреждение / грушпа } & \multirow{2}{*}{ иноземщы } & \multicolumn{4}{|c|}{ русские } & \multirow{2}{*}{$\Delta \mathrm{V}^{*}$} \\
\hline & & I гр. & ІІ гр. & III гр. & IV гр. & \\
\hline BTC & $-11,4$ & $+51,4$ & $-25,7$ & 0,0 & $-14,3$ & +48 \\
\hline Сенат & $-6,9$ & $+40,6$ & $-28,5$ & $+1,8$ & $-6,9$ & +71 \\
\hline коллегии, президенты & $+15,8$ & $-8,8$ & $-20,8$ & $+15,8$ & $-2,1$ & -22 \\
\hline коллегии, вице-президенты & $+7,9$ & 0,0 & 0,0 & $-7,9$ & 0,0 & +10 \\
\hline другие центральные учреждения & $-3,2$ & $+14,8$ & $-3,2$ & $+6,4$ & $-14,8$ & +42 \\
\hline губернаторы & $+23,2$ & $-1,6$ & $-39,7$ & $+24,8$ & $-6,6$ & +25 \\
\hline вице-губернаторы & $+21,7$ & 0,0 & $-12,1$ & $-9,6$ & 0,0 & -9 \\
\hline
\end{tabular}

Прим. : Каждый показатель - разность между средними значениями конца (1729-1730 гг.) и начала (1725-1726 гг.) периода. Заливкой выделены показатели ниже $(-10 \%)$, заливкой и полужирным начертанием - выше (+10\%).

* $\boldsymbol{\Delta} \mathrm{V}$ - изменение коэффициента вариации в течение периода (в процентах). 
ПРЕДСТАВЛЕННАЯ СТАТИСТИКА ПОЗВОЛЯЕТ СДЕЛАТЬ ВЫВОД О СУЩЕСТВЕННЫХ РАЗЛИЧИЯХ « КАДРОВОЙ ПОЛИТИКИ» В ЦАРСТВОВАНИЕ ЕКАТЕРИНЫ І И ПЕТРА ІІ. КАК ВИДИМ, ПРИ ПЕТРЕ ІІ ДВЕ СТРАТЫ ИЗ ПЯТИ БЫСТРО ТЕРЯЛИ СВОЕ ВЛИЯНИЕ В АППАРАТЕ УПРАВЛЕНИЯ. ЭТО БЫЛИ ПРЕДСТАВИТЕЛИ ФАМИЛИЙ, ПОПАВШИХ В ДУМУ В XVII СТОЛЕТИИ (II ГРУППА), И НЕДВОРЯНЕ (IV ГРУППА). ПРИМЕЧАТЕЛЬНО, ЧТО ПРОЦЕСС В ТОЙ ИЛИ ИНОЙ МЕРЕ ЗАТРОНУЛ АБСОЛЮТНО ВСЕ КАТЕГОРИИ ГОСУДАРСТВЕННЫХ УЧРЕЖДЕНИЙ : ОТ ВЫСШИХ И ЦЕНТРАЛЬНЫХ ОРГАНОВ ВЛАСТИ ДО ГУБЕРНСКОГО УРОВНЯ. РОДОВИТАЯ АРИСТОКРАТИЯ (І ГРУППА), КОТОРАЯ ПРИ ЕКАТЕРИНЕ І ПО ВСЕМ ПОЗИЦИЯМ УСТУПАЛА ДУМНЫМ ФАМИЛИЯМ XVII СТОЛЕТИЯ (II ГРУППА), В ПЕРИОД ПРАВЛЕНИЯ ПЕТРА II ЗНАЧИТЕЛЬНО УКРЕПИЛА СВОЕ ПОЛОЖЕНИЕ НА САМЫХ ВЕРХНИХ СТУПЕНЯХ АДМИНИСТРАТИВНОЙ ИЕРАРХИИ: В ВЕРХОВНОМ ТАЙНОМ СОВЕТЕ $(+51,4 \%)$, СЕНАТЕ (+40,6 \%) И, В МЕНЬШЕЙ СТЕПЕНИ, В ЦЕНТРАЛЬНЫХ УЧРЕЖДЕНИЯХ, НЕ ИМЕВШИХ КОЛЛЕЖСКОГО СТАТУСА (+14,8 \%). НАПРОТИВ, СРЕДИ ПРЕЗИДЕНТОВ КОЛЛЕГИЙ ДОЛЯ ЗНАТИ СНИЗИЛАСЬ $(-8,8 \%)$.

ДВОРЯНСКИЕ ФАМИЛИИ, НЕ ВХОДИВШИЕ В ДУМУ XVI-XVII ВВ. (III ГРУППА), УПРОЧИЛИ СВОЕ ВЛИЯНИЕ В РУКОВОДСТВЕ КОЛЛЕГИЙ $(+15,8$ \%) И СРЕДИ ГУБЕРНАТОРОВ $(+24,8 \%)$. ИНТЕРЕСНО, ЧТО К 1729-1730 ГГ. МОСКОВСКИЕ ЧИНЫ КОНТРОЛИРОВАЛИ ЧЕТВЕРТЬ СЕНАТА И ОТ ЧЕТВЕРТИ ДО ПОЛОВИНЫ ВЫСШИХ ДОЛЖНОСТЕЙ В ЦЕНТРАЛЬНОМ И МЕСТНОМ АППАРАТЕ. ЕДИНСТВЕННЫМ ИСКЛЮЧЕНИЕМ ЯВЛЯЛСЯ ВЕРХОВНЫЙ ТАЙНЫЙ СОВЕТ, КУДА ПРЕДСТАВИТЕЛИ ЭТОЙ ГРУППЫ НЕ НАЗНАЧАЛИСЬ.

ИНОЗЕМЦЫ, КОТОРЫЕ ТРАДИЦИОННО ПРЕОБЛАДАЛИ НА ПОСТАХ ВИЦЕ-ПРЕЗИДЕНТОВ КОЛЛЕГИЙ, ПРИ ПЕТРЕ II СМОГЛИ УКРЕПИТЬ СВОЕ ВЛИЯНИЕ СРЕДИ ГУБЕРНАТОРОВ $(+23,2 \%)$, ВИЦЕ-ГУБЕРНАТОРОВ $(+21,7 \%)$ И ГЛАВ КОЛЛЕГИЙ $(+15,8 \%)$. В СОСТАВЕ ВЕРХОВНИКОВ ИХ ДОЛЯ УМЕНЬШИЛАСЬ $(-11,4 \%)$.

СРАВНЕНИЕ КОЭФФИЦИЕНТОВ ВАРИАЦИИ (V) ПОКАЗЫВАЕТ, ЧТО СОЦИАЛЬНЫЙ СОСТАВ УПРАВЛЕНЧЕСКИХ СТРУКТУР ПРИ ЕКАТЕРИНЕ І БЫЛ БОЛЕЕ СБАЛАНСИРОВАННЫМ, ЧЕМ ПРИ ПЕТРЕ ІІ. К КОНЦУ ИЗУЧАЕМОГО ПЕРИОДА ДИСПРОПОРЦИИ НАРАСТАЮТ : ВЛАСТЬ КОНЦЕНТРИРУЕТСЯ В РУКАХ ПРЕДСТАВИТЕЛЕЙ ОДНИХ СОЦИАЛЬНЫХ ГРУПП В УЩЕРБ ДРУГИМ. ПЕРЕРАСПРЕДЕЛЕНИЕ ВЛАСТИ ОСУЩЕСТВЛЯЛОСЬ В ПОЛЬЗУ АРИСТОКРАТИИ (В ВЫСШИХ УЧРЕЖДЕНИЯХ), МОСКОВСКОГО ДВОРЯНСТВА И ИНОЗЕМЦЕВ (В ЦЕНТРАЛЬНЫХ И ГУБЕРНСКИХ). ПОЗИЦИИ ДУМНЫХ ФАМИЛИЙ XVII В. ЗНАЧИТЕЛЬНО ОСЛАБЛИ, А НЕДВОРЯНЕ, КОТОРЫЕ В ОЧЕНЬ РЕДКИХ СЛУЧАЯХ ПОПАДАЛИ В СОСТАВ ПРАВЯЩЕГО СЛОЯ ПРИ ПЕТРЕ ВЕЛИКОМ, ТЕПЕРЬ ПРАКТИЧЕСКИ ПОЛНОСТЬЮ ПОТЕРЯЛИ ВОЗМОЖНОСТЬ ЗАНИМАТЬ РУКОВОДЯЩИЕ ДОЛЖНОСТИ В АДМИНИСТРАЦИИ.

В КАКОЙ МЕРЕ ПРЕДСТАВЛЕННАЯ ДИНАМИКА МОЖЕТ БЫТЬ ОБЪЯСНЕНА С ПОМОЩЬЮ УПОМЯНУТОЙ ВЫШЕ ТРАДИЦИОННОЙ КОНЦЕПЦИИ СТОЛКНОВЕНИЯ «НОВОГО», ХУДОРОДНОГО ДВОРЯНСТВА (ПОБЕДИВШЕГО ПРИ ЕКАТЕРИНЕ І) И АРИСТОКРАТИЧЕСКОЙ « РУССКОЙ ПАРТИИ» (ВЫИГРАВШЕЙ БОРЬБУ ПРИ ПЕТРЕ II $)^{74}$ ? ПРИВЕДЕННЫЕ ДАННЫЕ ПОЗВОЛЯЮТ УВИДЕТЬ, ЧТО ЭТА ТЕОРИЯ ОЧЕНЬ СЛАБО ОТРАЖАЕТ ВСЮ ПАЛИТРУ ПЕРЕМЕН В СОСТАВЕ ЭЛИТЫ ИЗУЧАЕМОГО ПЕРИОДА. УСИЛЕНИЕ ЗНАТИ (А ТОЧНЕЕ, ОТДЕЛЬНЫХ ФАМИЛИЙ ИЗ ЭТОГО СЛОЯ) ПРИ ПЕТРЕ ІІ В ПОЛНОЙ МЕРЕ ЗАТРОНУЛО ЛИШЬ ДВА ВЫСШИХ ОРГАНА ВЛАСТИ - ВЕРХОВНЫЙ ТАЙНЫЙ СОВЕТ И СЕНАТ. В ЦЕНТРАЛЬНЫХ И ГУБЕРНСКИХ УЧРЕЖДЕНИЯХ НА СМЕНУ НЕРОДОВИТЫМ ДУМНЫМ ФАМИЛИЯМ XVII В. ПРИШЛО ЕЩЕ МЕНЕЕ РОДОВИТОЕ МОСКОВСКОЕ ДВОРЯНСТВО И ИНОЗЕМЦЫ. ПРИМЕЧАТЕЛЬНО, ЧТО УКРЕПЛЕНИЕ ПОЗИЦИЙ «НЕМЦЕВ» ПРОИЗОШЛО НЕ ПРИ ЕКАТЕРИНЕ I, КОГДА ПРИ 
РУССКОМ ДВОРЕ СУЩЕСТВОВАЛА ТАК НАЗЫВАЕМАЯ «ГОЛШТИНСКАЯ ГРУППИРОВКА» ${ }^{75}$, А УЖЕ ПРИ ПЕТРЕ II, ПРАВЛЕНИЕ КОТОРОГО РАСЦЕНИВАЛОСЬ КАК «ГОСПОДСТВО СТАРОРУССКОЙ ПАРТИИ». СЛЕДУЕТ ТАКЖЕ ПРИНЯТЬ ВО ВНИМАНИЕ, ЧТО ЛИЦА БЛИЗКОГО СОЦИАЛЬНОГО ПРОИСХОЖДЕНИЯ И ДАЖЕ ПРЕДСТАВИТЕЛИ ОДНОГО РОДА НЕ ВСЕГДА ПРИДЕРЖИВАЛИСЬ ОДИНАКОВЫХ ВЗГЛЯДОВ (В ТОМ ЧИСЛЕ, И ПОЛИТИЧЕСКИХ) ${ }^{76}$.

РАСПОЛАГАЯ ТОЧНЫМИ ДАННЫМИ ОБ ИЗМЕНЕНИЯХ СОСТАВА АДМИНИСТРАЦИИ 1725-1730 ГГ., МЫ МОЖЕМ БОЛЕЕ АДЕКВАТНО ОЦЕНИТЬ ПРОЕКТЫ НАЧАЛА 1730 Г., ОТРАЗИВШИЕ РЕАКЦИЮ «ШЛЯХЕТСТВА» НА ПОЛИТИЧЕСКУЮ СИТУАЦИЮ ВНУТРИ СТРАНЫ. НИ ОДИН ИЗ НИХ НЕ СТАВИЛ ПОД СОМНЕНИЕ ГЛАВНЫЕ ИДЕИ « ВЕРХОВНИКОВ» О ТОМ, ЧТО МОНАРХИЯ ЯВЛЯЕТСЯ ЕДИНСТВЕННО ВОЗМОЖНОЙ ФОРМОЙ ПРАВЛЕНИЯ, А САМОДЕРЖАВИЕ ДОЛЖНО БЫТЬ ОГРАНИЧЕНО. ТАКЖЕ НЕ ОБСУЖДАЛСЯ ВЫБОР КАНДИДАТУРЫ АННЫ ИОАННОВНЫ НА РОЛЬ НОВОЙ ИМПЕРАТРИЦЫ. АВТОРЫ ПРОЕКТОВ ПРИНЯЛИ ВО ВНИМАНИЕ НОВЫЕ ПОЛИТИЧЕСКИЕ РЕАЛИИ И МОЛЧАЛИВО С НИМИ СОГЛАСИЛИСЬ ${ }^{77}$. В КАКОЙ МЕРЕ ЭТО СОГЛАСИЕ ОТРАЖАЛО ИХ СОБСТВЕННЫЕ ВЗГЛЯДЫ И НАСКОЛЬКО ЭТИ ВОПРОСЫ ВООБЩЕ БЫЛИ СУЩЕСТВЕННЫ ДЛЯ ЭЛИТЫ, ОСТАЕТСЯ ТОЛЬКО ДОГАДЫВАТЬСЯ. ОДНАКО ОЧЕВИДНО, ЧТО КОНФИГУРАЦИЯ ВЛАСТИ, СЛОЖИВШАЯСЯ К НАЧАЛУ 1730 Г., НЕ ОТВЕЧАЛА ИНТЕРЕСАМ ЗНАЧИТЕЛЬНОЙ ЧАСТИ ПРАВЯЩЕГО СЛОЯ.

ШЕСТЬ ПРОЕКТОВ ТРЕБОВАЛИ РАСШИРЕНИЯ СОСТАВА ВЕРХОВНОГО ТАЙНОГО СОВЕТА (С 7 ДО 12-21 ЧЕЛОВЕКА $\left.{ }^{78}\right)$, А СЕДЬМОЙ (« ОБЩЕСТВА») ПРЕДПОЛАГАЛ ЕГО ЛИКВИДАЦИЮ. ПЯТЬ « МНЕНИЙ» (КРОМЕ ПРОЕКТОВ «5-ТИ» И И.А. МУСИНА-ПУШКИНА) НАСТАИВАЛИ НА УВЕЛИЧЕНИИ ЧИСЛА СЕНАТОРОВ - С 8 ДО 11 ИЛИ ДАЖЕ ДО 21-30 ЛИЦ. ПРОЕКТЫ ПРЕДЛАГАЛИ ПРИВЛЕЧЬ К ВЫБОРАМ ВО ВЛАСТНЫЕ СТРУКТУРЫ ПРЕДСТАВИТЕЛЕЙ « ОБЩЕСТВА», ПОД КОТОРЫМ ПОДРАЗУМЕВАЛИСЬ «ГЕНЕРАЛИТЕТ» (ВОЕННЫЙ И ШТАТСКИЙ) И « ШЛЯХЕТСТВО» (50-100 ЧЕЛОВЕК). ДЛЯ ОТБОРА КАНДИДАТОВ ДОЛЖНА БЫЛА ИСПОЛЬЗОВАТЬСЯ УЖЕ ИЗВЕСТНАЯ СО ВРЕМЕН ПЕТРА І ПРОЦЕДУРА БАЛЛОТИРОВАНИЯ. СОЗЫВ ПРЕДСТАВИТЕЛЕЙ « ОБЩЕСТВА» ДЛЯ ОБСУЖДЕНИЯ ВАЖНЫХ ГОСУДАРСТВЕННЫХ ДЕЛ ПРЕДПОЛАГАЛСЯ И ВПРЕДЬ. КОЛИЧЕСТВО ВЫХОДЦЕВ ИЗ ОДНОЙ « ФАМИЛИИ» В ОРГАНАХ УПРАВЛЕНИЯ ОГРАНИЧИВАЛОСЬ (СОГЛАСНО ШЕСТИ ПРОЕКТАМ) : ЛИБО НА ЭТАПЕ ФОРМИРОВАНИЯ ВЫБОРЩИКОВ И ВЫДВИЖЕНИЯ КАНДИДАТОВ, ЛИБО ПРЯМЫМ УКАЗАНИЕМ НА МАКСИМАЛЬНО ВОЗМОЖНУЮ ЧИСЛЕННОСТЬ ЕДИНОРОДЦЕВ В ТОМ ИЛИ ИНОМ УЧРЕЖДЕНИИ ${ }^{79}$. РОЛЬ ИНОЗЕМЦЕВ В СОБЫТИЯХ НАЧАЛА 1730 Г. БЫЛА НЕЗНАЧИТЕЛЬНА : ОНИ НЕ ПРИГЛАШАЛИСЬ НА ОГЛАШЕНИЕ КОНДИЦИЙ 2 ФЕВРАЛЯ 1730 Г., А ПОДПИСИ ЛИЦ С ИНОСТРАННЫМИ ФАМИЛИЯМИ ПОД «ШЛЯХЕТСКИМИ ПРОЕКТАМИ» Были Единичны ${ }^{80}$.

МЫ УЖЕ УПОМИНАЛИ, ЧТО ШЛЯХЕТСКИЕ ПРОЕКТЫ НЕ ТРЕБОВАЛИ ВОССТАНОВЛЕНИЯ БАЛЛОТИРОВКИ В АРМИИ ${ }^{81}$. АВТОРЫ ПРОЕКТОВ СОСРЕДОТОЧИЛИ СВОЕ ВНИМАНИЕ ИСКЛЮЧИТЕЛЬНО НА ВЫСШИХ СТАТСКИХ ЧИНАХ И ДОЛЖНОСТЯХ. ПРИЧИНУ ЭТОГО СЛЕДУЕТ ВИДЕТЬ В ТОМ, ЧТО ИМЕННО ЗДЕСЬ ВОЗМОЖНОСТИ КАРЬЕРНОГО РОСТА НЕРОДОВИТЫХ ДВОРЯН БЫЛИ САМЫМИ НИЗКИМИ. ТАК, В СТАТСКИХ ЧИНАХ 1-5 КЛАССОВ (1728-1730 ГГ.) ДОЛЯ ТРАДИЦИОННОЙ ЭЛИТЫ (I-II ГРУППЫ) СОСТАВЛЯЛА 60-64 \%, В АРМЕЙСКИХ - 43-48 \%, В МОРСКИХ - 29-44 \%, В ПРИДВОРНЫХ - 44-53 \% ${ }^{82}$. ВЛИЯНИЕ АРИСТОКРАТИИ (І ГРУППА) СРЕДИ СТАТСКИХ ТАКЖЕ БЫЛО СУЩЕСТВЕННЫМ - 35-40 \%. ДЛЯ СРАВНЕНИЯ, УДЕЛЬНЫЙ ВЕС ЗНАТИ В АРМЕЙСКОЙ ЭЛИТЕ СОСТАВЛЯЛ 17-18\%, МОРСКОЙ - 14-22\%, ПРИДВОРНОЙ - 19-32\%. СЛЕДОВАТЕЛЬНО, БАЛЛОТИРОВКА ПРИВЛЕКАЛА « ШЛЯХЕТСТВО» НЕ КАК АБСТРАКТНАЯ « ДЕМОКРАТИЧЕСКАЯ ПРОЦЕДУРА». 
ВЫБОРЫ И РАСШИРЕНИЕ СОСТАВА ОРГАНОВ ВЛАСТИ РАССМАТРИВАЛИСЬ «ШЛЯХЕТСТВОМ» КАК ИНСТРУМЕНТЫ, КОТОРЫЕ МОГЛИ ПОМОЧЬ КАРЬЕРНОМУ РОСТУ, ОБЛЕГЧИТЬ ДОСТУП К ВЫСОКИМ ДОЛЖНОСТЯМ И ОГРАНИЧИТЬ ПРЕИМУЩЕСТВА МОСКОВСКОЙ ЭЛИТЫ НА СТАТСКОЙ СЛУЖБЕ ${ }^{83}$.

ВНИМАНИЕ ДВОРЯНСТВА К ЧИСЛЕННОСТИ ПРЕДСТАВИТЕЛЕЙ ТЕХ ИЛИ ИНЫХ ФАМИЛИЙ В ГОСУДАРСТВЕННОМ АППАРАТЕ ВПОЛНЕ ОБЪЯСНИМО, ПОСКОЛЬКУ РОДСТВЕННЫЕ СВЯЗИ ОСТАВАЛИСЬ ВАЖНЫМ РЕГУЛЯТОРОМ ВЛАСТИ. КАК СПРАВЕДЛИВО ЗАМЕТИЛА В. КИВЕЛЬСОН, ЖЕЛАНИЕ «ШЛЯХЕТСТВА» ПРОТИВОДЕЙСТВОВАТЬ ЧРЕЗМЕРНОМУ УКРЕПЛЕНИЮ ОДНОЙ-ДВУХ ФАМИЛИЙ СООТВЕТСТВОВАЛО ТРАДИЦИЯМ « КЛАНОВОЙ ПОЛИТИКИ» МОСКОВСКОЙ РУСИ ${ }^{84}$. ОДНАКО НЕЛЬЗЯ СЧИТАТЬ, ЧТО ПОДПИСАНИЕ « ПРОЕКТОВ» БЫЛО ПРОДИКТОВАНО ИСКЛЮЧИТЕЛЬНО РОДСТВОМ ИЛИ ПАТРОНАЖЕМ ${ }^{85}$. ФОРМИРОВАНИЕ СЕТЕЙ ПАТРОНАЖА ЗАНИМАЛО ДЛИТЕЛЬНОЕ ВРЕМЯ. ПРИЗНАВ РЕШАЮЩУЮ РОЛЬ ЭТОГО ФАКТОРА, ПРИДЕТСЯ ДОПУСТИТЬ, ЧТО ЗАДОЛГО ДО СОБЫТИЙ НАЧАЛА 1730 Г. СЛОЖИЛАСЬ РАЗВЕТВЛЕННАЯ СЕТЬ, НАСЧИТЫВАВШАЯ БОЛЕЕ 350 ЧЛЕНОВ, КОТОРЫЕ ЖЕЛАЛИ ОГРАНИЧИТЬ ВЛИЯНИЕ « ВЕРХОВНИКОВ» И БЫЛИ НАСТОЛЬКО ХОРОШО ОРГАНИЗОВАНЫ, ЧТО СМОГЛИ В СЧИТАННЫЕ ДНИ МОБИЛИЗОВАТЬСЯ ДЛЯ ПОДПИСАНИЯ « ПРОЕКТА 364-Х». НА НАШ ВЗГЛЯД, ЭТО МАЛОВЕРОЯТНО. ПО ВСЕЙ ВИДИМОСТИ, « ПРОЕКТ БОЛЬШИНСТВА» СТАЛ ПОПУЛЯРНЫМ ПО ДРУГОЙ ПРИЧИНЕ : ОН СОДЕРЖАЛ ПРЕДЛОЖЕНИЯ, КОТОРЫЕ ОТСУТСТВОВАЛИ У ОСТАЛЬНЫХ. СОГЛАСНО ЭТОМУ ПРОЕКТУ, ВЫСШИЕ ОРГАНЫ ВЛАСТИ ВЫБИРАЛИСЬ СОБРАНИЕМ СТА ПЕРСОН» ИЗ ГЕНЕРАЛИТЕТА И ШЛЯХЕТСТВА, А ВЕРХОВНЫЙ ТАЙНЫЙ СОВЕТ ОТСТРАНЯЛСЯ ОТ УЧАСТИЯ В ЭТОЙ ПРОЦЕДУРЕ. «КОМПРОМИССНЫЕ» ВАРИАНТЫ (« 15-ТИ», « 25-ТИ» И « 13-ТИ»), СОХРАНЯВШИЕ ЗА «ВЕРХОВНИКАМИ» ПРАВО УТВЕРЖДЕНИЯ КАНДИДАТОВ, ПОЛУЧИЛИ ЗНАЧИТЕЛЬНО МЕНЬШУЮ ПОДДЕРЖКУ ${ }^{86}$. ТАКИМ ОБРАЗОМ, ОСНОВНАЯ БОРЬБА В НАЧАЛЕ 1730 Г. ШЛА В ПЛОСКОСТИ КОНКУРЕНЦИИ «ИДЕЙ», А НЕ ПАТРОНАЖНЫХ СЕТЕЙ. ПОСЛЕДНИЕ НЕСОМНЕННО СУЩЕСТВОВАЛИ И ОКАЗЫВАЛИ СВОЕ ВОЗДЕЙСТВИЕ, НО ИХ ЭФФЕКТИВНОСТЬ ДЛЯ ОРГАНИЗАЦИИ « МАССОВОГО ВОЛЕИЗЪЯВЛЕНИЯ» БЫЛА НЕВЕЛИКА. БОЛЕЕ СУЩЕСТВЕННЫЕ РЕЗУЛЬТАТЫ ЗДЕСЬ ДАВАЛИ « АДМИНИСТРАТИВНЫЙ РЕСУРС» И ИСПОЛЬЗОВАНИЕ « КОРПОРАТИВНОЙ ПСИХОЛОГИИ», РАЗВИТОЙ В ГВАРДЕЙСКОЙ СРЕДЕ. НАПОМНИМ, ЧТО ИМЕННО ЭТИ ФАКТОРЫ СЫГРАЛИ ВАЖНУЮ РОЛЬ ПРИ ПОДПИСАНИИ ГВАРДЕЙЦАМИ И КАВАЛЕРГАРДАМИ ПРОШЕНИЯ О ВОССТАНОВЛЕНИИ САМОДЕРЖАВИЯ 25 ФЕВРАЛЯ 1730 Г. ${ }^{87}$

НЕЖЕЛАНИЕ ВЕРХОВНОГО ТАЙНОГО СОВЕТА ИДТИ НА ОГРАНИЧЕНИЕ СВОЕЙ ВЛАСТИ В ПОЛЬЗУ БОЛЕЕ ШИРОКОГО КРУГА ЛИЦ, ОПАСЕНИЕ «ТИРАНИИ ЗНАТНЫХ ФАМИЛИЙ ${ }^{88}$, РАСПРОСТРАНЕННОЕ В ДВОРЯНСКОЙ СРЕДЕ, И ПРИЕЗД АННЫ ИОАННОВНЫ В МОСКВУ ОСЛАБИЛИ ПОЗИЦИИ «ВЕРХОВНИКОВ». СПУСТЯ ТРИ НЕДЕЛИ ПОСЛЕ НАЧАЛА ПОДАЧИ ПРОЕКТОВ, ДВОРЯНЕ ПРЕДПОЧЛИ БОЛЕЕ ПРИВЫЧНЫЙ ТИП ПРАВЛЕНИЯ. ЭТИ СОБЫТИЯ СТАЛИ РЕАКЦИЕЙ НА ПОПЫТКУ ДВУХ ДРЕВНИХ И МОГУЩЕСТВЕННЫХ ФАМИЛИЙ НАРУШИТЬ СЛОЖИВШИЕСЯ ПРАВИЛА ПОЛИТИЧЕСКОЙ ИГРЫ. ОТКАЗ ДОЛГОРУКОВЫХ И ГОЛИЦЫНЫХ ОТ КОМПРОМИССА ПОДТОЛКНУЛ ЭЛИТУ К ВОССТАНОВЛЕНИЮ САМОДЕРЖАВИЯ. ОНО ДОЛЖНО БЫЛО СТАТЬ АРБИТРОМ В БОРЬБЕ КЛАНОВ, СОХРАНИТЬ ЕДИНСТВО ПОЛИТИЧЕСКОЙ СИСТЕМЫ И ОБЕСПЕЧИТЬ ПРИЕМЛЕМЫЙ БАЛАНС СИЛ ПРИ РАСПРЕДЕЛЕНИИ ВЫСШИХ ДОЛЖНОСТЕЙ ${ }^{89}$. ЗАДАЮТСЯ ВОПРОСОМ : ПО КАКИМ ПРИЧИНАМ ШЛЯХЕТСТВО, В ТЕЧЕНИЕ МЕСЯЦА СТОЛЬ 
АКТИВНО ОБСУЖДАВШЕЕ НОВУЮ ФОРМУ ПРАВЛЕНИЯ, В КОНЦЕ КОНЦОВ ПОДДЕРЖАЛО ВОССТАНОВЛЕНИЕ АБСОЛЮТНОЙ МОНАРХИИ? НА НАШ ВЗГЛЯД, ЭТОТ ПОДХОД ОСНОВАН НА ЛОЖНОМ ПРЕДСТАВЛЕНИИ О СПОСОБНОСТИ УЧАСТНИКОВ ДВИЖЕНИЯ СДЕЛАТЬ ОСОЗНАННЫЙ ВЫБОР МЕЖДУ РАЗЛИЧНЫМИ ТИПАМИ ОБЩЕСТВЕННОГО УСТРОЙСТВА. ОЧЕВИДНО, ЧТО УРОВЕНЬ П ПОЛИТИЧЕСКОЙ ГРАМОТНОСТИ» БОЛЬШЕЙ ЧАСТИ ПРАВЯЩЕГО СЛОЯ БЫЛ ДАЛЕК ОТ ЭТОГО ${ }^{90}$. В ДЕЙСТВИТЕЛЬНОСТИ, ПРЕДСТАВИТЕЛИ ЭЛИТЫ ВЫБИРАЛИ НЕ ПОЛИТИЧЕСКОЕ БУДУЩЕЕ И ФОРМУ ПРАВЛЕНИЯ ДЛЯ СТРАНЫ, ОНИ ВЫБИРАЛИ ДРУГОЕ - МЕСТО ВО ВЛАСТИ ДЛЯ СЕБЯ, СВОИХ РОДСТВЕННИКОВ (КЛАНА) И СВОЕГО ОКРУЖЕНИЯ. ЭТО В РАВНОЙ МЕРЕ ОТНОСИЛОСЬ КО ВСЕМ УЧАСТНИКАМ СОБЫТИЙ : ЧЛЕНАМ ВЕРХОВНОГО ТАЙНОГО СОВЕТА, «ШЛЯХЕТСТВУ» И СТОРОННИКАМ АННЫ ИОАННОВНЫ. БЛИЗОСТЬ К ПРАВИТЕЛЮ - ИСТОЧНИКУ ВЛАСТИ, ПРИВИЛЕГИЙ И МАТЕРИАЛЬНЫХ БЛАГ ЯВЛЯЛАСЬ ГЛАВНЫМ МЕРИЛОМ СОЦИАЛЬНОГО СТАТУСА В МОСКОВСКОЙ РУСИ И ИМПЕРАТОРСКОЙ РОССИИ. ПОЭТОМУ ЭЛИТА 1730 Г. ДЕЛАЛА ВЫБОР НЕ МЕЖДУ « КОНСТИТУЦИОНАЛИЗМОМ» И «САМОДЕРЖАВИЕМ». ПРОБЛЕМА ФОРМУЛИРОВАЛАСЬ В ИНОМ КЛЮЧЕ : СОГЛАСЕН ЛИ ПРАВЯЩИЙ СЛОЙ ПОДДЕРЖАТЬ АМБИЦИИ ДОЛГОРУКОВЫХ И ГОЛИЦЫНЫХ, СДЕЛАВ ЭТИ ДВА КЛАНА ЦЕНТРОМ ВЛАСТИ И НОВОЙ ПОЛИТИЧЕСКОЙ СИСТЕМЫ, И ЕСЛИ - ДА, ТО КАКОВА « ЦЕНА» ЭТОЙ ПОДДЕРЖКИ.

ОЧЕВИДНО, ЧАСТЬ ЭЛИТЫ, КОТОРАЯ СОСТАВЛЯЛА И ПОДПИСЫВАЛА ПРОЕКТЫ, БЫЛА ГОТОВА ОБСУЖДАТЬ ЭТОТ ВОПРОС. ВЗАМЕН ОНА ТРЕБОВАЛА УЧАСТИЯ В ФОРМИРОВАНИИ ВЫСШИХ ОРГАНОВ ВЛАСТИ, РАСШИРЕНИЯ ИХ СОСТАВА И ОГРАНИЧЕНИЯ ДИКТАТА ОДНОЙ-ДВУХ ФАМИЛИЙ. ЭТО БЫЛА НЕ ТОЛЬКО « ПРОГРАММА» РАЗВИТИЯ НА БУДУЩЕЕ, НО И СВОЕОБРАЗНЫЙ ВЗГЛЯД В ПРОШЛОЕ, КРИТИЧЕСКАЯ ОЦЕНКА ПРЕДШЕСТВУЮЩЕГО ЦАРСТВОВАНИЯ. ПОСКОЛЬКУ ПЕТР ІІ, УЖЕ В СИЛУ СВОЕГО ВОЗРАСТА, БЫЛ НЕСПОСОБЕН ЭФФЕКТИВНО УПРАВЛЯТЬ ЭЛИТОЙ, ТО ВЛАСТЬ СКОНЦЕНТРИРОВАЛАСЬ В РУКАХ ОГРАНИЧЕННОГО КРУГА ЛИЦ ${ }^{91}$. КРОМЕ ТОГО, ПРАВЛЕНИЕ ПЕТРА ІІ ПРИВЕЛО К ИЗМЕНЕНИЮ БАЛАНСА СИЛ НА ВСЕХ УРОВНЯХ ВЛАСТНОЙ ПИРАМИДЫ - ОТ ВЫСШИХ И ЦЕНТРАЛЬНЫХ УЧРЕЖДЕНИЙ ДО ГУБЕРНСКИХ (ТАБЛ. 10-12) - И ЗАТРОНУЛО ИНТЕРЕСЫ ЗНАЧИТЕЛЬНОЙ ЧАСТИ ЭЛИТЫ. ИМЕННО НА ЭТИ ПРОБЛЕМЫ «ШЛЯХЕТСТВО» ОБРАТИЛО ВНИМАНИЕ В СВОИХ ПРОЕКТАХ (ЕСТЕСТВЕННО, В ЗАВУАЛИРОВАННОЙ ФОРМЕ). ПОСЛЕ СМЕРТИ ЮНОГО ГОСУДАРЯ И СОСТАВЛЕНИЯ «КОНДИЦИЙ» «ШЛЯХЕТСТВУ» И ГЕНЕРАЛИТЕТУ БЫЛО ПРЕДЛОЖЕНО ПОДДЕРЖАТЬ, И ТЕМ САМЫМ УЗАКОНИТЬ, УЖЕ СЛОЖИВШУЮСЯ de facto ВЕДУЩУЮ РОЛЬ ДВУХ КЛАНОВ. КАК ИЗВЕСТНО, НИ НА КАКИЕ СУЩЕСТВЕННЫЕ УСТУПКИ «ОБЩЕСТВУ» ВЕРХОВНИКИ ИДТИ НЕ ЗАХОТЕЛИ. С ЭТОЙ ТОЧКИ ЗРЕНИЯ, К КОНЦУ ФЕВРАЛЯ РЕАЛЬНОГО ВЫБОРА У ЭЛИТЫ УЖЕ НЕ ОСТАВАЛОСЬ. В ЧЕЛОБИТНУЮ 25 ФЕВРАЛЯ 1730 Г. О «ВОССТАНОВЛЕНИИ САМОДЕРЖАВИЯ» ВОШЛИ ПРЕЖНИЕ ИДЕИ ДВОРЯНСКИХ « МНЕНИЙ» О РАСШИРЕНИИ СЕНАТА И УЧАСТИИ «ШЛЯХЕТСТВА» В ВЫБОРАХ ${ }^{92}$. АННА ИОАННОВНА ПРОЯВИЛА БОЛЬШЕ СКЛОННОСТИ К КОМПРОМИССУ, В ТОМ ЧИСЛЕ С ТОЙ ЧАСТЬЮ ЭЛИТЫ, КОТОРАЯ УЧАСТВОВАЛА В ПОДАЧЕ ПРОЕКТОВ. ВПРОЧЕМ, «УСТУПЧИВОСТЬ» ИМПЕРАТРИЦЫ БЫЛА ВРЕМЕННОЙ И В ОСНОВНОМ КАСАЛАСЬ « КАДРОВЫХ ВОПРОСОВ». НА ОГРАНИЧЕНИЕ СВОИХ ПРЕРОГАТИВ И СОЗЫВ ПРЕДСТАВИТЕЛЕЙ « ОБЩЕСТВА» ОНА УЖЕ НЕ ПОШЛА. 


\section{NOTES}

1. ИССЛЕДОВАНИЕ ВЫПОЛНЕНО ПРИ ФИНАНСОВОЙ ПОДДЕРЖКЕ РГНФ, ПРОЕКТ № 14-01-00011(А).

2. ПОДРОБНЫЙ ИСТОРИОГРАФИЧЕСКИЙ ОБЗОР СМ. : И.В. КУРУКИН, А.Б. ПЛОТНИКОВ, 19 ЯНВАРЯ 25 ФЕВРАЛЯ 1730 ГОДА : СОБЫТИЯ, ЛЮДИ, ДОКУМЕНТЫ, М., 2010, С. 7-23.

3. А.Д. ГРАДОВСКИЙ, ВЫСШАЯ АДМИНИСТРАЦИЯ РОССИИ ХVIII СТ. И ГЕНЕРАЛ-ПРОКУРОРЫ, СПБ., 1866, С. 138, 145-146, 165 ; А.Н. ФИЛИППОВ, ИСТОРИЯ СЕНАТА В ПРАВЛЕНИЕ ВЕРХОВНОГО ТАЙНОГО СОВЕТА И КАБИНЕТА, Ч. 1, ЮРЬЕВ, 1895, С. 26-29 ; В.О. КЛЮЧЕВСКИЙ, РУССКАЯ ИСТОРИЯ : ПОЛНЫЙ КУРС ЛЕКЦИЙ, КН. 3, М., 1993, С. 115 ; П.Н. МИЛЮКОВ, ГОСУДАРСТВЕННОЕ ХОЗЯЙСТВО РОССИИ В ПЕРВОЙ ЧЕТВЕРТИ ХVIII СТОЛЕТИЯ И РЕФОРМА ПЕТРА ВЕЛИКОГО, СПБ., 1905, С. 505 ; В.Н. СТРОЕВ, БИРОНОВЩИНА И КАБИНЕТ МИНИСТРОВ : ОЧЕРК ВНУТРЕННЕЙ ПОЛИТИКИ ИМПЕРАТРИЦЫ АННЫ, Ч. 1, М., 1909, С. 10-20 ; С.Ф. ПЛАТОНОВ, ЛЕКЦИИ ПО РУССКОЙ ИСТОРИИ, М., 1993, С. 544-546.

4. А.Г. БРИКНЕР, « РУССКИЙ ДВОР ПРИ ПЕТРЕ II, 1727-1730 : ПО ДОКУМЕНТАМ ВЕНСКОГО АРХИВА», ВЕСТНИК ЕВРОПЫ, СПБ., 1896, КН. І (ЯНВАРЬ), С. 112, 114 ; СПБ., 1896, КН. ІІ (ФЕВРАЛЬ), С. 557-558, 583-586, 588, 592, 593, 598 ; СПБ., 1896, КН. ІІІ (МАРТ), С. 8-9, 19, 34 ; Б.Л. ВЯЗЕМСКИЙ, ВЕРХОВНЫЙ ТАЙНЫЙ СОВЕТ, СПБ., 1909, С. 55 ; А.Д. ГРАДОВСКИЙ, ВЫСШАЯ АДМИНИСТРАЦИЯ..., С. 143.

5. П.И. ПАВЛЕНКО, «БОРЬБА ЗА ВЛАСТЬ ВНУТРИ ГОСПОДСТВУЮЩЕГО КЛАССА», ОЧЕРКИ ИСТОРИИ СССР. ПЕРИОД ФЕОДАЛИЗМА : РОССИЯ ВО ВТОРОЙ ЧЕТВЕРТИ ХVIII В., М., 1957, С. 247-251.

6. П.Н. МИЛЮКОВ, «ВЕРХОВНИКИ И ШЛЯХЕТСТВО», ИЗ ИСТОРИИ РУССКОЙ ИНТЕЛЛИГЕНЦИИ, СПБ., 1902, С. 1-51 ; Я.А. ГОРДИН, МЕЖ РАБСТВОМ И СВОБОДОЙ : 19 ЯНВАРЯ - 25 ФЕВРАЛЯ 1730 Г., СПБ., 1994.

7. Е.В. АНИСИМОВ, ВНУТРЕННЯЯ ПОЛИТИКА ВЕРХОВНОГО ТАЙНОГО СОВЕТА (1726-1730), АВТОРЕФ. ... КАНД. ИСТ. НАУК, Л., 1975 ; ОН ЖЕ, ПОДАТНАЯ РЕФОРМА ПЕТРА І : ВВЕДЕНИЕ ПОДУШНОЙ ПОДАТИ В РОССИИ, 1719-1728 ГГ., Л., 1982, С. 259-286 ; ОН ЖЕ, РОССИЯ БЕЗ ПЕТРА : 1725-1740, СПБ., 1994, С. 20-21, 99-103 ; А.Б. КАМЕНСКИЙ, ОТ ПЕТРА I ДО ПАВЛА І. РЕФОРМЫ В РОССИИ ХVIII ВЕКА : ОПЫТ ЦЕЛОСТНОГО АНАЛИЗА, М., 1999, С. 212-213 ; И.В. КУРУКИН, ЭПОХА «ДВОРСКИХ БУРЬ»: ОЧЕРКИ ИСТОРИИ ПОСЛЕПЕТРОВСКОЙ РОССИИ, 1725-1762 ГГ., РЯЗАНЬ, 2003, С. 75, 137, 139-140, 143-144 ; КУРУКИН, ПЛОТНИКОВ, 19 ЯНВАРЯ - 25 ФЕВРАЛЯ 1730 ГОДА... ; D. Ransel, « Political Perceptions of the Russian Nobility: The Constitutional Crisis of 1730», Laurentian University Review, 3, 1972, c. 20-38 ; Idem, "The Government Crisis of 1730», in R.O. Crummey, ed., Reform in Russia and the USSR: Past and Prospects, Urbana, 1989, c. 45-71; V. Kivelson, «Kinship Politics/Autocratic Politics: A Reconsideration of Early-Eighteenth-Century Political Culture», in J. Burbank, D. Ransel, eds., Imperial Russia : New Histories for The Empire, Bloomington : Indiana Univ. Press, 1998, c. 5-31.

8. B. Meehan-Waters, «The Muscovite Noble Origins of the Russians in the Generalitet of 1730", Cahiers du Monde russe et soviétique, 12 (1-2), 1971, c. 28-75; Idem, «The Russian Aristocracy and the Reforms of Peter the Great», Canadian-American Slavic Studies, 8 (2-Summer), 1974, c. 288-302 ; Idem, "Social and career characteristics of the administrative elite, 1689-1761», in W. McKenzie Pinter, D.K. Rowney, eds., Russian officialdom: the bureaucratization of Russian society from the seventeenth to the twentieth century, London: Macmillan Press, 1980, c. 76-105 ; Idem, Autocracy and aristocracy: The Russian Service Elite of 1730, New Brunswick, New Jersey : Rutgers univ. press, 1982. СРЕДИ ПОСЛЕДНИХ ФУНДАМЕНТАЛЬНЫХ РАБОТ ВЫДЕЛИМ СЛЕДУЮЩИЕ: КУРУКИН, ЭПОХА « ДВОРСКИХ БУРЬ»... ; М.В. БАБИЧ, И.В. БАБИЧ, СОСТ., ОБЛАСТНЫЕ ПРАВИТЕЛИ РОССИИ, 1719-1739 ГГ., M., 2008.

9. В НАСТОЯЩЕЙ РАБОТЕ ИСПОЛЬЗОВАЛАСЬ СОСТАВЛЯЕМАЯ МНОЙ БИОГРАФИЧЕСКАЯ БАЗА ДАННЫХ ПО ЭЛИТЕ 1725-1762 ГГ. ОСНОВНЫЕ ИСТОЧНИКИ: РОССИЙСКИЙ ГОСУДАРСТВЕННЫЙ АРХИВ ДРЕВНИХ АКТОВ (ДАЛЕЕ - РГАДА), Ф. 16, оП. 1, КН. 36, 38, 81, 101, 168 ; Ф. 20, оП. 1, КН. 20, 
21, 61, 219 ; Ф. 199, порТФ. 240, д. 15-16 ; Ф. 210, оп. 21, кН. 1087 ; оп. 22, кН. 209 ; Ф. 248, Кн. 21, $33,46,380,387,391,413,421,424,428,605,606,608,689,768,985,1088,1155,1353,1933-1942$, 1947, 1950-1952, 6416 ; Ф. 286, оп. 1, кн. 45, 49, 63, 75, 82, 106, 108, 117, 119, 122, 125, 133, 143, $167,170,181,182,208,216,222,238,239,245,260,262,310,331,418,419,421$; Ф. 350, оп. 3 , КН. 1 ; РОССИЙСКИЙ ГОСУДАРСТВЕННЫЙ ВОЕННО-ИСТОРИЧЕСКИЙ АРХИВ, Ф. 489. ОП. 1, КН. 7134, 7339, 7386-7388, 7395 ; Ф. 490, оп. 2, кн. 6-8, 13, 20, 21, 33-35, 37, 38, 41, 42, 44, 45, 47, 50-53, 55, 56, 58 ; СБОРНИК ИМПЕРАТОРСКОГО РУССКОГО ИСТОРИЧЕСКОГО ОБЩЕСТВА (ДАЛЕЕ - СБ. РИО), СПБ., 1886-1898, т. 55, 56, 63, 69, 79, 84, 94, 101.

10. Г.А. ПРОТАСОВ, «ДВОРЯНСКИЕ ПРОЕКТЫ 1730 ГОДА (ИСТОЧНИКОВЕДЧЕСКОЕ ИЗУЧЕНИЕ)», ИСТОЧНИКОВЕДЧЕСКИЕ РАБОТЫ, ВЫП. 2, ТАМБОВ, 1971, С. 63, 68-76, 101-102; КУРУКИН, ПЛОТНИКОВ, 19 ЯНВАРЯ - 25 ФЕВРАЛЯ 1730 ГОДА..., С. 46-49, 115.

11. ПРОЦЕДУРА КОМПЛЕКТОВАНИЯ ПРИДВОРНЫХ ЧИНОВ ПОЧТИ НЕ ПРИВЛЕКЛА ВНИМАНИЯ ДВОРЯНСТВА (УПОМИНАНИЕ ОБ ЭТОМ ЕСТЬ ЛИШЬ В ПРОЕКТЕ «ОБЩЕСТВА»). КАКИХ-ЛИБО ПЕРЕМЕН В НАЗНАЧЕНИИ ВЫСШЕГО ВОЕННОГО КОМАНДОВАНИЯ « ШЛЯХЕТСКИЕ ПРОЕКТЫ» НЕ ПРЕДУСМАТРИВАЛИ ВОВСЕ. ПО ЭТИМ ПРИЧИНАМ, ВОПРОСЫ ЭВОЛЮЦИИ АРМЕЙСКОГО ГЕНЕРАЛИТЕТА, МОРСКИХ И ПРИДВОРНЫХ ЧИНОВ СОЗНАТЕЛЬНО ОСТАВЛЕНЫ ЗА РАМКАМИ ЭТОЙ СТАТЬИ.

12. ОБ ОБЩИХ ПРИНЦИПАХ КЛАССИФИКАЦИИ СМ. : С.В. ЧЕРНИКОВ, « РОССИЙСКАЯ ЭЛИТА ЭПОХИ РЕФОРМ ПЕТРА ВЕЛИКОГО: СОСТАВ И СОЦИАЛЬНАЯ СТРУКТУРА», ГОСУДАРСТВО И ОБЩЕСТВО В РОССИИ ХV-НАЧАЛА ХХ ВЕКА, СПБ., 2007, С. 373-379. ДОПОЛНИТЕЛЬНО ПОДЧЕРКНЕМ, ЧТО ПРЕДЛОЖЕННАЯ «СОЦИАЛЬНАЯ ГРУППИРОВКА» (ПО ПРОИСХОЖДЕНИЮ) НИКАК НЕ СВЯЗАНА С « ЧИНОВНОЙ ИЕРАРХИЕЙ» ТОГО ВРЕМЕНИ - КЛАССАМИ ПЕТРОВСКОЙ ТАБЕЛИ О РАНГАХ 1722 Г.

13. С.А. ПЕТРОВСКИЙ, О СЕНАТЕ В ЦАРСТВОВАНИЕ ПЕТРА ВЕЛИКОГО, М., 1875, С. 58 ; ФИЛИППОВ, ИСТОРИЯ СЕНАТА..., С. 11-12.

14. « ЧТОБ, КРОМЕ ДВУХ ВОИНСКИХ КОЛЕГЕЙ И ИНОСТРАННОЙ, ВЫБРАТЬ ИНЫХ ПРЕЗИДЕНТОВ ; ... НАДЛЕЖАЛО Б И В БЕРГ-КОЛЕГИЮ, НО ЗАОБЫЧНОГО НЕ ЗНАЮ, ТОГО РАДИ, ПОКА ТАКОЙ СЫЩЕТСЯ, БЫТЬ ПО СТАРОМУ». - Н.А. ВОСКРЕСЕНСКИЙ, ЗАКОНОДАТЕЛЬНЫЕ АКТЫ ПЕТРА I, М.-Л., 1945, С. 245.

15. Е.В. АНИСИМОВ, ГОСУДАРСТВЕННЫЕ ПРЕОБРАЗОВАНИЯ И САМОДЕРЖАВИЕ ПЕТРА ВЕЛИКОГО В ПЕРВОЙ ЧЕТВЕРТИ ХVIII ВЕКА, СПБ., 1997, С. 243-244.

16. Я.В. БРЮС ТАКЖЕ ВОЗГЛАВЛЯЛ КАНЦЕЛЯРИЮ ГЛАВНОЙ АРТИЛЛЕРИИ.

17. П.И. БАРАНОВ, СОСТ., ОПИСЬ ВЫСОЧАЙШИМ УКАЗАМ И ПОВЕЛЕНИЯМ, ХРАНЯЩИМСЯ В С.-ПЕТЕРБУРГСКОМ СЕНАТСКОМ АРХИВЕ (ДАЛЕЕ - БАРАНОВ), Т. ІІ, СПБ., 1875, № 1639, С. 11. ПО УКАЗУ 8 ФЕВРАЛЯ 1726 Г. СЕНАТ БЫЛ ПОДЧИНЕН ВЕРХОВНОМУ ТАЙНОМУ СОВЕТУ (СЕНАТ БЫЛ ОБЯЗАН НАПРАВЛЯТЬ СОВЕТУ « ДОНОШЕНИЯ», А СОВЕТ СЕНАТУ - « УКАЗЫ»). ПОСКОЛЬКУ РУКОВОДИТЕЛИ ВОЕННОЙ, АДМИРАЛТЕЙСКОЙ И ИНОСТРАННОЙ КОЛЛЕГИЙ ВОШЛИ В ВЕРХОВНЫЙ ТАЙНЫЙ СОВЕТ, ТО С ЭТИМИ ТРЕМЯ КОЛЛЕГИЯМИ СЕНАТ ДОЛЖЕН БЫЛ «СНОСИТЬСЯ ПРОМЕМОРИЯМИ» (КАК С УЧРЕЖДЕНИЯМИ РАВНЫМИ ПО СТАТУСУ). - РГАДА, Ф. 248, КН. 1938, Л. 235, 237 ОБ. ПОЛНОЕ СОБРАНИЕ ЗАКОНОВ РОССИЙСКОЙ ИМПЕРИИ С 1649 ГОДА. СОБР. 1, СПБ., 1830 (ДАЛЕЕ - ПСЗ), Т. VII, № 4830 , С. 569 ; СБ. РИО, Т. 55, С. 2.

18. СБ. РИО, Т. 55, С. 22. ПРИ РАСЧЕТАХ П.И. ЯГУЖИНСКИЙ НЕ УЧИТЫВАЛСЯ КАК ЧЛЕН СОВЕТА.

19. СБ. РИО, Т. 55, С. 49 ; ФИЛИППОВ, ИСТОРИЯ СЕНАТА..., С. 39. В ИЗДАНИИ « ОБЛАСТНЫЕ ПРАВИТЕЛИ РОССИИ» УКАЗАНО, ЧТО 19 АПРЕЛЯ 1726 Г. ЧЛЕНОМ СОВЕТА БЫЛ НАЗНАЧЕН КН. И.Г. ДОЛГОРУКОВ, НО ЭТО НАЗНАЧЕНИЕ «ПО-ВИДИМОМУ, НЕ СОСТОЯЛОСЬ» (ОБЛАСТНЫЕ ПРАВИТЕЛИ..., С. 301). ПО НАШИМ ДАННЫМ, ЧЛЕНОМ ВЕРХОВНОГО ТАЙНОГО СОВЕТА И.Г. ДОЛГОРУКОВ НЕ НАЗНАЧАЛСЯ ВОВСЕ, А 18 АПРЕЛЯ 1726 Г. ОН БЫЛ ОПРЕДЕЛЁН В СОВЕТ В КАЧЕСТВЕ ПЕРЕВОДЧИКА ГЕРЦ. К.-Ф.ГОЛШТИНСКОГО (К ПРИСЯГЕ ПРИВЕДЕН НА СЛЕДУЮЩИЙ ДЕНЬ - 19 АПРЕЛЯ). - СБ. РИО, Т. 55, С. 211-212, 217, 229, 320, 331, 340, 361. 
20. П.А. ТОЛСТОЙ ПОСЛЕДНИЙ РАЗ ПРИСУТСТВОВАЛ НА ЗАСЕДАНИИ 26 АПРЕЛЯ, ГЕРЦ. К.-Ф. ГОЛШТИНСКИЙ - 16 ИЮНЯ, КН. А.Д. МЕНШИКОВ - 7 СЕНТЯБРЯ 1727 Г. (ВЯЗЕМСКИЙ, ВЕРХОВНЫЙ ТАЙНЫЙ СОВЕТ, С. 399, 400, 402).

21. СБ. РИО, Т. 84, С. 643. ПОСЛЕДНЕЕ ЗАСЕДАНИЕ, НА КОТОРОМ ПРИСУТСТВОВАЛ Ф.М. АПРАКСИН, ПРОХОДИЛО У НЕГО ДОМА 15 ОКТЯБРЯ 1728 Г. - ВЯЗЕМСКИЙ, ВЕРХОВНЫЙ ТАЙНЫЙ СОВЕТ, С. 408.

22. БАРАНОВ, Т. ІІ, № 2854, С. 132 ; СБ. РИО, т. 79, С. 87 ; т. 101, С. 427 ; КУРУКИН, ПЛОТнИКОВ, 19 ЯНВАРЯ - 25 ФЕВРАЛЯ 1730 ГОДА..., С. 152. Б.Л. ВЯЗЕМСКИЙ И И.В. КУРУКИН СПРАВЕДЛИВО УКАЗЫВАЮТ, ЧТО БЫВШИЙ СИБИРСКИЙ ГУБЕРНАТОР КН. М.В. ДОЛГОРУКОВ НИКОГДА ЧЛЕНОМ СОВЕТА НЕ БЫЛ (ВЯЗЕМСКИЙ, ВЕРХОВНЫЙ ТАЙНЫЙ СОВЕТ, С. 66; КУРУКИН, ЭПОХА «ДВОРСКИХ БУРЬ»..., С. 173). В ОДНОЙ ИЗ РЕДАКЦИЙ « ФОРМЫ ПРАВЛЕНИЯ», СОСТАВЛЕННОЙ ВЕРХОВНИКАМИ В ФЕВРАЛЕ 1730 Г., ПРЯМО УКАЗЫВАЕТСЯ, ЧТО В СОВЕТЕ «НЫНЕ» ПРИСУТСТВУЕТ « 7 ОСОБ» (КУРУКИН, ПЛОТНИКОВ, 19 ЯНВАРЯ - 25 ФЕВРАЛЯ 1730 ГОДА..., С. 227). ДО НАЧАЛА 1730 Г. КН. А.Г. ДОЛГОРУКОВ КРАЙНЕ РЕДКО УЧАСТВОВАЛ В РАБОТЕ СОВЕТА. С МАРТА 1728 Г. ДО КОНЦА 1729 Г. ОН ПОСЕТИЛ ЛИШЬ 5 ЗАСЕДАНИЙ, В ЯНВАРЕ-ФЕВРАЛЕ 1730 Г. - 12. ПРИЧИНЫ ЧАСТЫХ ПРОПУСКОВ ЗАСЕДАНИЙ В 1728-1729 ГГ. ВПОЛНЕ ОЧЕВИДНЫ, ПОСКОЛЬКУ ЕГО МОГУЩЕСТВО ЗАВИСЕЛО В ПЕРВУЮ ОЧЕРЕДЬ ОТ ЛИЧНОГО ВЛИЯНИЯ НА ГОСУДАРЯ (ВЯЗЕМСКИЙ, ВЕРХОВНЫЙ ТАЙНЫЙ СОВЕТ, С. 58, 90-91, 413-414).

23. В ЛИТЕРАТУРЕ, ПОСВЯЩЕННОЙ СЕНАТУ, ЕСТЬ РАЗНОЧТЕНИЯ И, КАК ВЫЯСНИЛОСЬ, ОШИБОЧНЫЕ СВЕДЕНИЯ О ЕГО СОСТАВЕ В 1725-1730 ГГ. НАИМЕНЬШЕЙ ПОЛНОТОЙ И ТОЧНОСТЬЮ ОБЛАДАЮТ ДАННЫЕ О СЕНАТОРАХ В ПРАВЛЕНИЕ ЕКАТЕРИНЫ І. ПОЭТОМУ ДЛЯ АНАЛИЗА СОСТАВА ЭТОГО УЧРЕЖДЕНИЯ БЫЛИ ПРИВЛЕЧЕНЫ СЕНАТСКИЕ ЖУРНАЛЫ И ПРОТОКОЛЫ ЗА НОЯБРЬ 1724-МАЙ 1725 ГГ. И ЯНВАРЬ-МАРТ 1726 Г., ОТЛОЖИВШИЕСЯ В ФОНДАХ РГАДА.

24. ПОДСЧИТАНО ПО ПРОТОКОЛАМ СЕНАТА ЗА НОЯБРЬ 1724-МАЙ 1725 ГГ. (ПО ДАТАМ « КРЕПЛЕНИЯ» ПРОТОКОЛОВ) И КНИГЕ « ПИСЬМЕННЫХ И СЛОВЕСТНЫХ ПРИКАЗОВ» ГОСУДАРЯ ЗА 1724 Г., СОСТАВЛЕННОЙ В ЖУРНАЛЬНОЙ ФОРМЕ (ФИКСИРОВАЛА ПОСЕЩЕНИЕ ЗАСЕДАНИЙ). РГАДА, Ф. 248, КН. 1933-1942.

25. РГАДА, Ф. 248, КН. 1933, Л. 95 ОБ. ; КН. 1934, Л. 13, 59 ОБ.

26. НАЧАЛ ПОСЕЩАТЬ ЗАСЕДАНИЯ С 20 АВГУСТА 1724 Г. - РГАДА, Ф. 248, КН. 1935, Л. 110, 114. УКАЗАНИЕ, ЧТО КН. А.И. РЕПНИН НАЧАЛ ПОДПИСЫВАТЬ СЕНАТСКИЕ ПРОТОКОЛЫ ТОЛЬКО С 23 ОКТЯБРЯ 1724 Г. (АНИСИМОВ, ГОСУДАРСТВЕННЫЕ ПРЕОБРАЗОВАНИЯ..., С. 245), ОШИБОЧНО.

27. РГАДА, Ф. 248, КН. 1935, Л. 228 ; КН. 1934, Л. 34-35. НАЗНАЧЕНИЕ КН. Г.Д. ЮСУПОВА БЫЛО СЛЕДСТВИЕМ УКАЗА ПЕТРА І ОТ 5 ДЕКАБРЯ 1724 Г. : « ПОНЕЖЕ В СЕНАТЕ НЫНЕ МАЛО ЧЛЕНОФ ОБРЕТАЕТЦА, ТОГО РАДИ 3 ПЕРСОНЫ ПРИБАВТЕ ИЗ ГЕНЕРАЛИТЕТУ И ПЕРЕМЕНЯТЦА ИМ ПОГОДНО» (СБ. РИО, Т. 11, С. 563).

28. РГАДА, Ф. 248, КН. 1937, Л. 116-116 ОБ. ПЕРЕД ЭТИМ ПОСЛЕДНИЙ РАЗ ПОДПИСЫВАЛ ПРОТОКОЛЫ 25 МАЯ 1724 Г. (РГАДА, Ф. 248, КН. 1936, Л. 24-25), ПОСЛЕДНИЙ РАЗ ПРИСУТСТВОВАЛ НА ЗАСЕДАНИИ 4 ИЮНЯ 1724 Г. (РГАДА, Ф. 248, КН. 1935, Л. 93 ОБ.).

29. РГАДА, Ф. 248, КН. 1937, Л. 178-179, 180-181 ОБ. ПЕРЕД ЭТИМ ПОСЛЕДНИЙ РАЗ ПРИСУТСТВОВАЛ НА ЗАСЕДАНИЯХ И ПОДПИСЫВАЛ ПРОТОКОЛЫ В ОКТЯБРЕ 1724 Г. (РГАДА, Ф. 248, Кн. 1935, л. 154 оБ., 157 оБ-158, 161-162, 164-164 оБ., 167 ; кн. 1936, л. 73, 76 оБ., 79, 80-80 оБ., 82,83 оь.-84, 87, 88-89, 90, 91-93).

30. РГАДА, Ф. 248, КН. 1937, Л. 184 ; КН. 1938, Л. 22 ОБ. ПЕРЕД ЭТИМ ПОСЛЕДНИЙ РАЗ ПОДПИСЫВАЛ ПРОТОКОЛЫ 19 ОКТЯБРЯ 1724 Г. (РГАДА, Ф. 248, КН. 1936, Л. 88-89, 90, 91-93), ПРИСУТСТВОВАЛ НА ЗАСЕДАНИИ - 21 ОКТЯБРЯ 1724 Г. (РГАДА, Ф. 248, КН. 1935, Л. 167).

31. РГАДА, Ф. 248, КН. 1940, Л. 141, 142, 143-145 ОБ., 147 ОБ., 149 ОБ., 151 ОБ. ; КН. 1938, Л. 63 оБ., 64 ОБ. В МАРТЕ 1725 Г. КН. А.И. РЕПНИН БЫЛ НАЗНАЧЕН ГЕНЕРАЛ-ГУБЕРНАТОРОМ РИЖСКОЙ ГУБЕРНИИ. 
32. РГАДА, Ф. 248, КН. 1938, Л. 44. ПОСЛЕ 17 ФЕВРАЛЯ 1725 Г. ПРОТОКОЛЫ СЕНАТА НЕ ПОДПИСЫВАЛ, А В ИЮЛЕ 1725 Г. БЫЛ НАЗНАЧЕН ГЛАВОЙ СЕНАТСКОЙ КОНТОРЫ В МОСКВЕ.

33. РГАДА, Ф. 248, КН. 1939, Л. 2. В РАБОТЕ И.В. КУРУКИНА УКАЗАНА БОЛЕЕ ПОЗДНЯЯ ДАТА - 2 ФЕВРАЛЯ 1725 Г. (КУРУКИН, ЭПОХА « ДВОРСКИХ БУРЬ»..., С. 97).

34. СМ. : ФИЛИППОВ, ИСТОРИЯ СЕНАТА..., С. 18 ; КУРУКИН, ЭПОХА « ДВОРСКИХ БУРЬ»..., С. 97, 105. А.В. ДЕМКИН, ВНУТРЕННЯЯ ПОЛИТИКА ЕКАТЕРИНЫ І И ВЕРХОВНОГО ТАЙНОГО СОВЕТА, М., 2011, С. 21 (КРОМЕ ТОГО, ОШИБОЧНО НАЗВАН ГЕНЕРАЛ-МАЙОРОМ). МНЕНИЕ ИСТОРИКОВ О НАЗНАЧЕНИИ И.И. БУТУРЛИНА В СЕНАТ ОСНОВАНО НА СООБЩЕНИЯХ ИНОСТРАННЫХ ДИПЛОМАТОВ. ТАК, В ДОНЕСЕНИИ ФРАНЦУЗСКОГО ПОСЛАННИКА Ж. ДЕ КАМПРЕДОНА ОТ 13 ФЕВРАЛЯ 1725 Г. УКАЗАНО, ЧТО ЕКАТЕРИНА І «НАЗНАЧИЛА ДВУХ СЕНАТОРОВ, ВПОЛНЕ ЕЙ ПРЕДАННЫХ. ОДИН ИЗ НИХ БУТУРЛИН, ГЕНЕРАЛ-ПОРУЧИК (sic!) И КОМАНДИР ГВАРДИИ, КОТОРОМУ ОНА ПОЖАЛУЕТ ОРДЕН СВ. АНДРЕЯ, ДРУГОЙ УШАКОВ, МАЙОР ТОЙ ЖЕ ГВАРДИИ» (СБ. РИО, Т. 58, С. 1). В ДОКУМЕНТАХ ТОГО ВРЕМЕНИ И.И. БУТУРЛИН УПОМИНАЕТСЯ КАК «ГЕНЕРАЛ», «ГВАРДИИ ПОДПОЛКОВНИК», «КОМАНДИР ПЕРВОЙ ПЕХОТНОЙ ДИВИЗИИ», НО НИ РАЗУ НЕ УКАЗАН КАК СЕНАТОР (РГАДА, Ф. 248, кн. 1939, л. 175 ; кн. 1940, л. 125, 142 ; кн. 1941, л. 218 ; кн. 1942, л. 73, 105 ; походный ЖУРНАЛ 1725 ГОДА, СПБ., 1855, С. 50 ; Ф.-В. БЕРХГОЛЬЦ, « ДНЕВНИК КАМЕР-ЮНКЕРА», ЮНОСТЬ ДЕРЖАВЫ, М., 2000, С.313, 316). ОЧЕВИДНО, ЕСЛИ НАЗНАЧЕНИЕ И.И. БУТУРЛИНА В СЕНАТ ПЕРВОНАЧАЛЬНО И ПЛАНИРОВАЛОСЬ, ТО ОНО НЕ СОСТОЯЛОСЬ. ОРДЕН СВ. АНДРЕЯ ПЕРВОЗВАННОГО БЫЛ ПОЖАЛОВАН И.И. БУТУРЛИНУ 21 МАЯ 1725 Г. (ПОХОДНЫЙ ЖУРНАЛ 1725 ГОДА, C. 50).

35. ЭТИ СЕНАТОРЫ ЧАСТО ПРОПУСКАЛИ ЗАСЕДАНИЯ И В БОЛЕЕ РАННЕЕ ВРЕМЯ. В 1723 Г. Я.В. БРЮС ПОСЕТИЛ ЛИШЬ 1,2 \% ОТ ОБЩЕГО ЧИСЛА СЕНАТСКИХ СОБРАНИЙ, И.А. МУСИН-ПУШКИН - 6,6 \%, А.Д. МЕНШИКОВ - 21,8 \% (АНИСИМОВ, ГОСУДАРСТВЕННЫЕ ПРЕОБРАЗОВАНИЯ..., С. 247).

36. РГАДА, Ф. 248, КН. 1938, Л. 92, 111, 113-114 ОБ., 116.

37. СБ. РИО, Т. 56 , С. 602 ; ФИЛИППОВ, ИСТОРИЯ СЕНАТА..., С. 176. В ПОМОЩЬ ГР. И.А. МУСИНУ-ПУШКИНУ 1 СЕНТЯБРЯ 1725 Г. В МОСКОВСКУЮ СЕНАТСКУЮ КОНТОРУ В РАНГЕ АСЕССОРА БЫЛ ОПРЕДЕЛЕН ЕГО СЫН - ПЛАТОН ИВАНОВИЧ (РГАДА, Ф. 16, КН. 81, Л. 47). УКАЗАНИЕ НА ТО, ЧТО ГР. П.И. МУСИН-ПУШКИН В ЭТО ВРЕМЯ ЯВЛЯЛСЯ СЕНАТОРОМ (ОБЛАСТНЫЕ ПРАВИТЕЛИ..., С. 476), ОШИБОЧНО. СОГЛАСНО « ИНСТРУКЦИИ СЕНАТСКОМУ ЧЛЕНУ, В МОСКВЕ БУДУЩЕМУ», В СОСТАВЕ СЕНАТСКОЙ КОНТОРЫ ДОЛЖНЫ БЫЛИ НАХОДИТЬСЯ ОДИН СЕНАТОР (ЕЕ ГЛАВА) И ДВА АСЕССОРА (АНИСИМОВ, ГОСУДАРСТВЕННЫЕ ПРЕОБРАЗОВАНИЯ..., С. 269).

38. ПОДПИСИ А.А. МАТВЕЕВА ПОД ПРОТОКОЛАМИ СЕНАТА 29 СЕНТЯБРЯ 1725 Г. СМ. : РГАДА, Ф. 248, КН. 1938, Л. 190, 191 ОБ. В ОКТЯБРЕ 1725 Г. ОН УПОМИНАЕТСЯ КАК « БЫВШИЙ» ГЛАВА СЕНАТСКОЙ КОНТОРЫ (РГАДА, Ф. 248, КН. 1947, л. 16).

39. РГАДА, Ф. 248, КН. 1938, Л. 219 ОБ.-222.

40. ПОДСЧИТАНО ПО ДАТАМ «КРЕПЛЕНИЯ» ПРОТОКОЛОВ СЕНАТА ЗА ЯНВАРЬ-МАРТ 1726 Г. И КНИГЕ СЕКРЕТНЫХ ПРОТОКОЛОВ ЗА 1725-АПРЕЛЬ 1726 ГГ. - РГАДА, Ф. 248, КН. 1938, 1950-1952.

41. БАРАНОВ, Т. ІІ, № 1639, С.11. ПОСЛЕДНИЕ ПОДПИСИ ПЯТИ НОВОИСПЕЧЕННЫХ ЧЛЕНОВ ТАЙНОГО СОВЕТА ПОД СЕНАТСКИМИ ПРОТОКОЛАМИ ДАТИРУЮТСЯ БОЛЕЕ ПОЗДНЕЙ ДАТОЙ - 18 ФЕВРАЛЯ 1726 Г. (РГАДА, Ф. 248, КН. 1951, Л. 63, 64 ОБ., 67).

42. СБ. РИО, Т. 55, С. 203-204, 253, 271; ФИЛИППОВ, ИСТОРИЯ СЕНАТА..., С. 226. УКАЗ БЫЛ ПОВТОРЕН 17 МАЯ 1726 Г. (ПСЗ, Т. VII, № 4886, С. 651), А 28 ОКТЯБРЯ 1726 Г. РЕВИЗИЯ БЫЛА РАСПРОСТРАНЕНА НА « БЛИЖНИЕ» К МОСКОВСКОЙ ГУБЕРНИИ « ГОРОДЫ» (СБ. РИО, Т. 56, С. 310). А.А. МАТВЕЕВ ПОСЛЕДНИЙ РАЗ ПОДПИСЫВАЛ ПРОТОКОЛЫ СЕНАТА 9 ФЕВРАЛЯ 1726 Г. (РГАДА, Ф. 248 , Кн. 1951, Л. 21 оБ., 23 ОБ., 25 ОБ., 27, 29, 30, 31 оБ., 33, 34 оБ., 37, 39, 40, 42, 43, 44, 45 оБ., $47,48,49,50,51$ оь., 53, 54, 55 оь., 58,59 оь.).

43. БАРАНОВ, Т. II, № 1639 , С. 11. 
44. В РЯДЕ ИССЛЕДОВАНИЙ ПО ИСТОРИИ СЕНАТА (А.Н. ФИЛИППОВА И Н.А. МУРЗАНОВА) НАЗНАЧЕНИЕ 8 ФЕВРАЛЯ 1726 Г. ВНОВЬ ОШИБОЧНО ПРИПИСЫВАЕТСЯ ГЕНЕРАЛ-АНШЕФУ ИВАНУ ИВАНОВИЧУ БУТУРЛИНУ. - ИСТОРИЯ ПРАВИТЕЛЬСТВУЮЩЕГО СЕНАТА ЗА ДВЕСТИ ЛЕТ, 1711-1911, СПБ., 1911, Т. 1, С. 384 ; Т.5, С.116. ЕЩЕ В ОДНОЙ РАБОТЕ ОН УПОМИНАЕТСЯ КАК «Д. СТ. СОВ. И.И. БУТУРЛИН», НАЗНАЧЕННЫЙ СЕНАТОРОМ ЕЩЕ В ФЕВРАЛЕ 1725 Г. - ФИЛИППОВ, ИСТОРИЯ СЕНАТА..., С. 18, 225. В СВОЕМ ДОНЕСЕНИИ 23 ФЕВРАЛЯ 1726 Г. Ж. ДЕ КАМПРЕДОН ТАКЖЕ ОШИБСЯ, НАЗВАВ ЕГО « le général Boutourline» (ГЕНЕРАЛ БУТУРЛИН). - СБ. РИО, Т. 64, С. 255.

НА САМОМ ДЕЛЕ, В СЕНАТ 8 ФЕВРАЛЯ 1726 Г. БЫЛ НАЗНАЧЕН ИВАН ФЕДОРОВИЧ БУТУРЛИН. ОН РОДИЛСЯ В 1686 Г. (В 1722 г. ЕМУ ИСПОЛНИЛОСЬ 36 ЛЕТ). ПОСТУПИЛ НА СЛУЖБУ В 1704 Г. ДО СВОЕГО НАЗНАЧЕНИЯ В СЕНАТ ЯВЛЯЛСЯ ПОЛКОВНИКОМ, ГВАРДИИ КАПИТАН-ЛЕЙТЕНАНТОМ (ИЛИ КАПИТАНОМ), ПРЕЗИДЕНТОМ КОММЕРЦ-КОЛЛЕГИИ (С 18 ЯНВАРЯ 1722 Г. ДО 22 ИЮЛЯ 1725 Г.), А 27 АВГУСТА 1725 Г. БЫЛ ПОЖАЛОВАН ИЗ ПОЛКОВНИКОВ В ДЕЙСТВИТЕЛЬНЫЕ СТАТСКИЕ СОВЕТНИКИ (ПАТЕНТ НА ЧИН ПОДПИСАН 9 СЕНТЯБРЯ 1725 Г.). НА СВАДЬБЕ КНЯЗЬ-ПАПЫ П.И. БУТУРЛИНА (10 СЕНТЯБРЯ 1721 Г.) ИЗ-ЗА СВОЕЙ ТУЧНОСТИ В ШУТКУ БЫЛ ВЫБРАН СКОРОХОДОМ. ПО ДАННЫМ «КНИГИ ПРИЕЗДОВ» СМОТРА СТОЛЬНИКА С.А. КОЛЫЧОВА, ЗА БУТУРЛИНЫМ ЧИСЛИЛСЯ 141 КРЕСТЬЯНСКИЙ ДВОР (ЗАПИСЬ ОТ 16 ЯНВАРЯ 1722 Г.). УМЕР И.Ф. БУТУРЛИН В 1726 Г. ЕГО ЖЕНУ ЗВАЛИ МАРФОЙ ЯКОВЛЕВНОЙ. - СЕНАТСКИЙ АРХИВ, Т. VII, СПБ., 1895, С. 652 ; РГАДА, Ф. 248, КН. 1161, Л. 799-799 ОБ., 1459 ОБ.; КН. 1935, л. 14, 23, 226, 240 ; Ф. 286 , оп. 1 , кн. 32 , л. 215 ; СБ. РИо, т. 11 , с. 447 ; т. 55 , с. 430, 438-439, 458 ; т. 63, с. 363-364 ; Т. 94, с. 750 ; Т. 114, С. 271 ; ПОХОДНЫЙ ЖУРНАЛ 1725 ГОДА, С. 31-32 ; ПОХОДНЫЙ ЖУРНАЛ 1721 ГОДА, С. 74 ; БАРАНОВ, Т. І, № 950, С. 83 ; т. 2 , № 1810 , С. 28 ; В.А. НАЩОКИН, «ЗАПИСКИ», В А. ЛИБЕРМАН, В. НАУМОВ, СОСТ., ИМПЕРИЯ ПОСЛЕ ПЕТРА, 1725-1765, М., 1998, С. 231.

45. РГАДА, Ф. 248, КН. 1951, Л. 62.

46. ПОДПИСИ И.Ф. БУТУРЛИНА ПОД ДОНОШЕНИЯМИ ИЗ СЕНАТА СМ. : СБ. РИО, Т. 55, С. 383, 437, 446, 453. ПО ДАННЫМ А.Н. ФИЛИППОВА, « И.И. БУТУРЛИН» ПЕРЕСТАЛ ПОДПИСЫВАТЬ ДОКУМЕНТЫ СЕНАТА С ИЮЛЯ 1726 Г. - ФИЛИППОВ, ИСТОРИЯ СЕНАТА..., С. 227.

47. ПРОТОКОЛЫ ПОДПИСАННЫЕ 9 ФЕВРАЛЯ 1726 Г. СМ. : РГАДА, Ф. 248, КН. 1951, Л. 21 ОБ., 23 ОБ., 25 оБ., 27, 29, 30, 31 оБ., 33, 34 оБ., 37, 39, 40, 42, 43, 44, 45 оБ., 47, 48, 49, 50, 51 оБ., 53, 54, 55 оБ., 58, 59 ОБ. ПО ДАННЫМ Ж. ДЕ КАМПРЕДОНА (ДОНЕСЕНИЕ ОТ 23 ФЕВРАЛЯ 1726 Г.), ГЕНЕРАЛ-МАЙОРЫ УШАКОВ И ЮСУПОВ ИЗ СЕНАТА БЫЛИ УДАЛЕНЫ, А НА ИХ МЕСТО НАЗНАЧЕНЫ МАЙОРЫ ГВАРДИИ ДМИТРИЕВ-МАМОНОВ И САЛТЫКОВ. - СБ. РИО, Т. 64, С. 255. В ИЗДАНИИ «ПРОТОКОЛОВ, ЖУРНАЛОВ И УКАЗОВ ВЕРХОВНОГО ТАЙНОГО СОВЕТА», СРЕДИ ПОДПИСАВШИХ ДОНОШЕНИЯ СЕНАТА, ОТ 16 МАРТА 1726 Г. УКАЗАН НЕКТО « КОЛТОВСКИЙ». - СБ. РИО, Т. 55, С. $103,184,188,192,193,194$. ОЧЕВИДНО, ЧТО ЭТО ОШИБКА ПУБЛИКАТОРОВ, КОТОРЫЕ НЕВЕРНО ПРОЧЛИ ПОДПИСЬ КН. А.Г. ДОЛГОРУКОВА (СМ. ПРОТОКОЛЫ ЗА МАРТ 1726 Г. - РГАДА, Ф. 248, КН. 1952). ПРОТОКОЛ 16 МАРТА 1726 Г. ПОДПИСАЛИ С.А.САЛТЫКОВ, А.М. ДЕВИЕР, А.Г. ДОЛГОРУКОВ, А.М. ЧЕРКАССКИЙ, И.И. ДМИТРИЕВ-МАМОНОВ (РГАДА, Ф. 248, КН. 1952, Л. 141-143).

48. НАЗНАЧЕН 16 МАРТА, ПРИВЕДЕН К ПРИСЯГЕ 23 МАРТА 1726 Г. - СБ. РИО, Т. 55, С. 92, 134 ; БАРАНОВ, Т. ІІ, № 1685, С. 16. НАЧАЛ ПОДПИСЫВАТЬ ПРОТОКОЛЫ СЕНАТА С 28 МАРТА 1726 Г. РГАДА, Ф. 248, КН. 1952, Л. 241 ОБ. ЗА В.Я. НОВОСИЛЬЦЕВЫМ БЫЛ ТАКЖЕ СОХРАНЕН ПОСТ ПРЕЗИДЕНТА МАНУФАКТУР-КОЛЛЕГИИ. - СБ. РИО, Т. 55, С. 46, 92, 134. ПОСЛЕ ТОГО КАК МАНУФАКТУР-КОЛЛЕГИЯ ВОШЛА В СОСТАВ КОММЕРЦ-КОЛЛЕГИИ (24 ФЕВРАЛЯ 1727 Г.), НОВОСИЛЬЦЕВ ВЕДАЛ « МАНУФАКТУРНЫЕ ДЕЛА» ПРИ СЕНАТЕ (С МАРТА 1727 Г.). ГОСУДАРСТВЕННОСТЬ РОССИИ, КН. 3, М., 2001, С. 37 ; СБ. РИО, Т. 63, С. 300, 362-363 ; БАРАНОВ, Т. II, № 2155, , .64.

49. НАЗНАЧЕН И ПРИВЕДЕН К ПРИСЯГЕ 23 МАРТА 1726 Г. - БАРАНОВ, Т. ІІ, № 1685, С. 16 ; СБ. РИО, Т. 55, С. 134 ; Т. 56, С. 59 ; Т. 63, С. 363 ; ИСТОРИЯ ПРАВИТЕЛЬСТВУЮЩЕГО СЕНАТА..., Т. 5, С. 140. 
НАЧАЛ ПОДПИСЫВАТЬ ПРОТОКОЛЫ СЕНАТА С 28 МАРТА 1726 Г. - РГАДА, Ф. 248, КН. 1952, Л. 241 оБ.

50. НАЗНАЧЕН 13 МАЯ 1726 Г. (ИЗ СОВЕТНИКОВ КАМЕР-КОЛЛЕГИИ). - СБ. РИО, Т. 56, С. 60, 250 ; Т. 63, С. 363. ПРИВЕДЕН К ПРИСЯГЕ 15 ИЮНЯ 1726 Г. - СБ. РИО, Т. 55, С. 362 . У Н.А. МУРЗАНОВА УКАЗАНА ОШИБОЧНАЯ ДАТА НАЗНАЧЕНИЯ - 16 АВГУСТА 1726 Г. (ИСТОРИЯ ПРАВИТЕЛЬСТВУЮЩЕГО СЕНАТА..., Т. 5, С. 139).

51. Д.О. СЕРОВ, АДМИНИСТРАЦИЯ ПЕТРА I, М., 2007, С. 38.

52. НАПРАВЛЕН В МАЛОРОССИЮ ПО УКАЗУ 20 ИЮНЯ 1727 Г., А 22 ИЮЛЯ 1727 Г. НАЗНАЧЕН « МИНИСТРОМ» ПЕТРА ІІ ПРИ ГЕТМАНЕ Д.П. АПОСТОЛЕ. - СБ. РИО, Т. 63, С. 779 ; БАРАНОВ, Т. ІІ, № 2456, С. 93. С АВГУСТА 1727 Г. ПОДПИСИ Ф.В. НАУМОВА В СЕНАТСКИХ МАТЕРИАЛАХ УЖЕ НЕ ВСТРЕЧАЮТСЯ. - ФИЛИППОВ, ИСТОРИЯ СЕНАТА..., С. 228.

53. ФИЛИППОВ, ИСТОРИЯ СЕНАТА..., С. 228.

54. ВОПРОС О ЗАМЕНЕ И.А. МУСИНА-ПУШКИНА В МОСКОВСКОЙ СЕНАТСКОЙ КОНТОРЕ ОБСУЖДАЛСЯ ЕЩЕ С ЛЕТА 1726 Г. - СБ. РИО, Т. 55, С. 404 ; Т. 56, С. 32, 72, 602. ОДНАКО В ДЕКАБРЕ 1726 Г. НАЗНАЧЕНИЕ И.А. МУСИНА-ПУШКИНА БЫЛО ВНОВЬ ПОДТВЕРЖДЕНО. - СБ. РИО, Т. 56, С. 590,601 ; БАРАНОВ, Т. II, № 2020, С. 49.

55. СБ. РИО, Т. 79, С. 330 ; Т. 84 , С. 193. ПОСЛЕДНЯЯ ПОДПИСЬ Ю.С. НЕЛЕДИНСКОГО-МЕЛЕЦКОГО ПОД ДОНОШЕНИЕМ ИЗ СЕНАТА ОТНОСИТСЯ К 20 МАЯ 1728 Г. - СБ. РИО, Т. 84, С. 199. ПО ДАННЫМ А.Н. ФИЛИППОВА, ОН ПЕРЕСТАЕТ ПОСЕЩАТЬ ЗАСЕДАНИЯ СЕНАТА В НАЧАЛЕ МАЯ. - ФИЛИППОВ, ИСТОРИЯ СЕНАТА... С. 230.

56. БАРАНОВ, Т. II, № 2965, С. 143 ; ФИЛИППОВ, ИСТОРИЯ СЕНАТА..., С. 229 ; ИСТОРИЯ ПРАВИТЕЛЬСТВУЮЩЕГО СЕНАТА..., Т. 5, С. 121. СМ. ТАКЖЕ: СБ. РИО, Т. 55, С. 46, 173. УКАЗ О НАЗНАЧЕНИИ БЫЛ «СКАЗАН» М.М. ГОЛИЦЫНУ 26 ИЮНЯ 1728 Г. - СБ. РИО, Т. 79, С. 544. НАЧАЛ ПРИСУТСТВОВАТЬ В СЕНАТЕ СО 2 ИЮЛЯ 1728 Г. - ФИЛИППОВ, ИСТОРИЯ СЕНАТА..., С. 230.

57. БАРАНОВ, Т. II, № 2965, С. 143 ; ФИЛИППОВ, ИСТОРИЯ СЕНАТА..., С. 229. ДО 23 ЯНВАРЯ 1730 Г. В СЕНАТЕ НЕ ПРИСУТСТВОВАЛ, ПОСКОЛЬКУ ЯВЛЯЛСЯ ПОЛНОМОЧНЫМ МИНИСТРОМ В ГОЛЛАНДИИ. - ФИЛИППОВ, ИСТОРИЯ СЕНАТА..., С. 230-231.

58. БАРАНОВ, Т. ІІ, № 2965, С. 143 . НАЧАЛ ПРИСУТСТВОВАТЬ С 17 ИЮНЯ 1728 Г. - ФИЛИППОВ, ИСТОРИЯ СЕНАТА..., С. 230. В ИЗДАНИИ « ОБЛАСТНЫЕ ПРАВИТЕЛИ» УКАЗАНО, ЧТО А.Л. ПЛЕЩЕЕВ УЖЕ НЕ ЯВЛЯЛСЯ СЕНАТОРОМ В НАЧАЛЕ 1730 Г. (ОБЛАСТНЫЕ ПРАВИТЕЛИ..., С. 529). ОДНАКО МОЖНО С УВЕРЕННОСТЬЮ УТВЕРЖДАТЬ, ЧТО ОН ОСТАВАЛСЯ В ЭТОЙ ДОЛЖНОСТИ ПО КРАЙНЕЙ МЕРЕ ДО 8 ФЕВРАЛЯ 1730 Г. (СМ. : КУРУКИН, ПЛОТНИКОВ, 19 ЯНВАРЯ - 25 ФЕВРАЛЯ 1730 ГОДА..., C. $160-161,169)$.

59. БАРАНОВ, Т. ІІ, № 2965, С. 143. ПРИВЕДЕН К ПРИСЯГЕ 18 НОЯБРЯ 1728 Г. - СБ. РИО, Т. 84, С. 660. НАЧАЛ ПРИСУТСТВОВАТЬ В СЕНАТЕ С 20 НОЯБРЯ 1728 Г. - ФИЛИППОВ, ИСТОРИЯ СЕНАТА..., С. 230.

60. СБ. РИО, Т. 84 , С. 431, 505-506. В КАЧЕСТВЕ ДАТЫ НАЗНАЧЕНИЯ ТАКЖЕ УПОМИНАЮТСЯ 4 СЕНТЯБРЯ (БАРАНОВ, Т. ІІ, № 3222, С. 168 ; ФИЛИППОВ, ИСТОРИЯ СЕНАТА..., С. 229 ; Г.А. ВЛАСЬЕВ, ПОТОМСТВО РЮРИКА, Т.І, Ч. 3, СПБ., 1907, С. 58 ; ИСТОРИЯ ПРАВИТЕЛЬСТВУЮЩЕГО СЕНАТА..., Т. 5, С. 124) И 10 СЕНТЯБРЯ 1728 Г. (СБ. РИО, Т. 84, С. 712). ПРИВЕДЕН К ПРИСЯГЕ 18 НОЯБРЯ 1728 Г. СБ. РИО, Т. 84, С. 660. НАЧАЛ ПРИСУТСТВОВАТЬ С 20 НОЯБРЯ 1728 Г. - ФИЛИППОВ, ИСТОРИЯ СЕНАТА ..., С. 230 .

61. БЕЗ УЧЕТА ИНОЗЕМЦЕВ. - С.В. ЧЕРНИКОВ, « СОСТАВ И ОСОБЕННОСТИ СОЦИАЛЬНОГО СТАТУСА СВЕТСКОЙ ПРАВЯЩЕЙ ЭЛИТЫ РОССИИ ПЕРВОЙ ЧЕТВЕРТИ XVIII ВЕКА : ТРАДИЦИИ И НОВАЦИИ», Cahiers $d u$ Monde russe, 51 (2-3), 2010, с. 272. В ПОСЛЕДНИЙ ГОД ЖИЗНИ ПЕТРА (1724Г.) СЕНАТОРАМИ ЯВЛЯЛИСЬ 11 ЧЕЛОВЕК: Ф.М. АПРАКСИН, Г.И.ГОЛОВКИН, П.А. ТОЛСТОЙ, В.Л. ДОЛГОРУКОВ, Д.М. ГОЛИЦЫН, А.А. МАТВЕЕВ, Я.В.БРЮС, А.Д. МЕНШИКОВ, А.И. РЕПНИН, г.д. Юсупов, и.А. мУсин-Пушкин. 
62. СМ. : Д.О. СЕРОВ, « ПРАВИТЕЛЬСТВУЮЩИЙ СЕНАТ В ПЕРВОЙ ЧЕТВЕРТИ ХVIII ВЕКА : КАДРОВЫЙ ВЫБОР ПЕТРА І», ПРАВЯЩИЕ ЭЛИТЫ И ДВОРЯНСТВО РОССИИ ВО ВРЕМЯ И ПОСЛЕ ПЕТРОВСКИХ РЕФОРМ (1682-1750), М., 2013, С. 119.

63. П. БУШКОВИЧ, ПЕТР ВЕЛИКИЙ : БОРЬБА ЗА ВЛАСТЬ, 1671-1725, СПБ., 2008, С. 345-432.

64. СЕРОВ, АДМИНИСТРАЦИЯ..., С. 263 ; ОН ЖЕ, «ПРАВИТЕЛЬСТВУЮЩИЙ СЕНАТ...», С. 105-106, 117-119; ЧЕРНИКОВ, “СОСТАВ И ОСОБЕННОСТИ...», р.267. ПО ДАННЫМ Д.О.СЕРОВА, ГР. А.Г. ГОЛОВКИН В СЕНАТЕ НЕ ПРИСУТСТВОВАЛ.

65. ЦГАДА. ПУТЕВОДИТЕЛЬ, Т. 2, М., 1992, С. 107-108.

66. ГР. П.М. АПРАКСИН (ЮСТИЦ), ГР. Ф.М. АПРАКСИН (АДМИРАЛТЕЙСКАЯ), А.П. АРСЕНЬЕВ (МАЛОРОССИЙСКАЯ, И.О. ГЛАВЫ), А.П. БАСКАКОВ (ЭКОНОМИИ), И.И.БИБИКОВ (РЕВИЗИОН), И.Ф. БУТУРЛИН (КОММЕРЦ), С.Л. ВЕЛЬЯМИНОВ (МАЛОРОССИЙСКАЯ), КН. М.М. МЛАДШИЙ ГОЛИЦЫН (ЮСТИЦ), ГР. Г.И. ГОЛОВКИН (ИНОСТРАННЫХ ДЕЛ), А.К.ЗЫБИН (БЕРГ, И.О. ГЛАВЫ, ЗАТЕМ ПРЕЗИДЕНТ), А.В. МАКАРОВ (КАМЕР), КН. А.Д. МЕНШИКОВ (ВОЕННАЯ), ГР. И.А. МУСИН-ПУШКИН (ШТАТС-КОНТОРА), А.Л. НАРЫШКИН (ШТАТС-КОНТОРА, ЗАТЕМ КАМЕР), Ф.В. НАУМОВ (РЕВИЗИОН, И.О. ГЛАВЫ), В.Я. НОВОСИЛЬЦЕВ (МАНУФАКТУР), А.Л. ПЛЕЩЕЕВ (КАМЕР), КН. А.И. РЕПНИН (ВОЕННАЯ), М.А.СУХОТИН (ВОТЧИННАЯ), ГР. И.П. ТОЛСТОЙ (ЮСТИЦ), БАР. П.П. ШАФИРОВ (КОММЕРЦ), КН. Г.Д. ЮСУПОВ (ВОЕННАЯ, ПЕРВЫЙ ЧЛЕН).

67. С.-А. ВОЛЬФ (ЮСТИЦ), К.И. КРЮЙС (АДМИРАЛТЕЙСКАЯ), М.-В.НИРОТ (КАМЕР), БАР. А.И. ОСТЕРМАН (ИНОСТРАННЫХ ДЕЛ), К. ПРИНЦЕНСТЕРН (ШТАТС-КОНТОРА, ЗАТЕМ КАМЕР), П.И. СИВЕРС (АДМИРАЛТЕЙСКАЯ), Г. ФИК (КОММЕРЦ).

68. В РЕВИЗИОН-КОЛЛЕГИИ А.Ю. БИБИКОВ ЯВЛЯЛСЯ « ТОВАРИЩЕМ» ЕЕ ГЛАВЫ - Ф.В. НАУМОВА.

69. « ВТОРОЙ» ВИЦЕ-ПРЕЗИДЕНТ.

70. ГР. Ф.М. АПРАКСИН, И.В. БОЛТИН, Г.И.БОН, А.П. ВОЛЫНСКИЙ, КН. В.И.ГАГАРИН, КН. М.В. ДОЛГОРУКОВ, И.Я. ДЮПРЕ, В.Н. ЗОТОВ, И.П. И П.В. ИЗМАЙЛОВЫ, П.П. ЛАССИ, И.М. ЛИХАРЕВ, П.Е. ЛОДЫЖЕНСКИЙ, ГР. А.А. МАТВЕЕВ, И.А. МЕНГДЕН (ФАМЕНДИН), КН. А.Д. МЕНШИКОВ, КН. С.Ф. МЕЩЕРСКИЙ, ГР. Б.-Х. МИНИХ, ГР. И.А. МУСИН-ПУШКИН, И.Я. НОВОСИЛЬЦЕВ, Е.И. ПАШКОВ, А.Л. ПЛЕЩЕЕВ, КН. А.И. РЕПНИН, Ю.А. РЖЕВСКИЙ, КН. И.Ф. РОМОДАНОВСКИЙ, ГР. Я.-К. САПЕГА, И.В. СТРЕКАЛОВ, А.М. СУХАРЕВ, К. ТОЛСТОЙ, КН. И.Ю. ТРУБЕЦКОЙ, КН. Ю.Ю. ТРУБЕЦКОЙ, Г.С. ХВОСТОВ, Г.П. ЧЕРНЫШЕВ, Л.Л. ШТОК.

71. Ф.Н. БАЛК, И.В. БОЛТИН, П.И. ВЕЛЬЯМИНОВ-ЗЕРНОВ, И.Л. И П.Л. ВОЕЙКОВЫ, КН. В.И. ГАГАРИН, В.В. ДЕЛДИН, И.И. ЗАХАРОВ, И.С. КАРАУЛОВ, Н.Н. И Н.А. КУДРЯВЦЕВЫ, П.И. ЛАЧИНОВ, Ф. ЛЕВЕН, П.Е. ЛОДЫЖЕНСКИЙ, А.И. ПАНИН, Е.И. ПАШКОВ, А.К. ПЕТРОВ-СОЛОВО, Ю.А. РЖЕВСКИЙ, И.В. СОНЦОВ-ЗАСЕКИН, И.В. СТРЕКАЛОВ, Л.Л. ШТОК.

72. НА РАЗЛИЧИЯ В СОСТАВЕ ГУБЕРНАТОРОВ ПРИГРАНИЧНЫХ ЗАПАДНЫХ ГУБЕРНИЙ, С ОДНОЙ СТОРОНЫ, И «ВНУТРЕННИХ», С ДРУГОЙ СТОРОНЫ, РАНЕЕ ОБРАТИЛА ВНИМАНИЕ Б. МИХАН-УОТЕРС. - Meehan-Waters, Autocracy and aristocracy..., с. 59-60.

73. Д.Н. БАНТЫШ-КАМЕНСКИЙ, БИОГРАФИИ РОССИЙСКИХ ГЕНЕРАЛИССИМУСОВ И ГЕНЕРАЛФЕЛЬДМАРШАЛОВ, Ч. 1, СПБ., 1840, С. 142-146. В ПЕРИОД СЕВЕРНОЙ ВОЙНЫ СОСТОЯЛ НА ШВЕДСКОЙ АРМЕЙСКОЙ СЛУЖБЕ. - ОБЛАСТНЫЕ ПРАВИТЕЛИ..., С. 574.

74. ФИЛИППОВ, ИСТОРИЯ СЕНАТА..., С. 26-29; КЛЮЧЕВСКИЙ, РУССКАЯ ИСТОРИЯ..., КН. 3, С. 115 ; МИЛЮКОВ, ГОСУДАРСТВЕННОЕ ХОЗЯЙСТВО..., С. 505 ; П.П. ЧЕРКАСОВ, Д.В. ЧЕРНЫШЕВСКИЙ, ИСТОРИЯ ИМПЕРАТОРСКОЙ РОССИИ ОТ ПЕТРА ВЕЛИКОГО ДО НИКОЛАЯ ІІ, М., 1994, С. 103 ; БУШКОВИЧ, ПЕТР ВЕЛИКИЙ..., С. 440-441, 452 ; Л.В. МИЛОВ, РЕД., ИСТОРИЯ РОССИИ ХVIII-ХІХ ВЕКОВ, М., 2008, С. 128.

75. БУШКОВИЧ, ПЕТР ВЕЛИКИЙ..., С. 440-442. П. БУШКОВИЧ СПРАВЕДЛИВО ЗАМЕТИЛ, ЧТО В НАЗВАНИИ « ПАРТИИ» ЕКАТЕРИНЫ (КАК ЕЕ ИМЕНОВАЛИ ИНОСТРАННЫЕ ДИПЛОМАТЫ) «БЫЛО НЕЧТО НЕ СОВСЕМ ПРАВИЛЬНОЕ», ПОСКОЛЬКУ ПО ГОЛШТИНСКОМУ ВОПРОСУ У СТОРОННИКОВ ИМПЕРАТРИЦЫ ПОЗИЦИИ РАЗЛИЧАЛИСЬ (ТАМ ЖЕ, С. 442, ПРИМ. 24). 
76. ОБ эТОМ СМ.: КУРУКИН, ЭПОХА «ДВОРСКИХ БУРњ».., С. 190-191; кУРУкИН, ПлОтникОВ, 19 ЯНВАРЯ - 25 ФЕВРАЛЯ 1730 ГОДА..., С. 73-76 ; Meehan-Waters, Autocracy and Aristocracy..., с. 159.

77. ОБ ЭТОМ СМ. : Kivelson, « Kinship Politics ...», c. 15.

78. И.А. МУСИН-ПУШКИН ВЫСКАЗАЛСЯ МЕНЕЕ ОПРЕДЕЛЕННО - « ПРИБАВИТЬ».

79. ПОМИМО ПРОБЛЕМЫ «СПРАВЕДЛИВОГО ПРЕДСТАВИТЕЛЬСТВА» В ОРГАНАХ ВЛАСТИ, ШЛЯХЕТСТВО ИНТЕРЕСОВАЛИ И СОЦИАЛЬНЫЕ ВОПРОСЫ (ОТМЕНА ЕДИНОНАСЛЕДИЯ, СУДЬБА ВЫМОРОЧНЫХ ИМЕНИЙ, СРОКИ И УСЛОВИЯ ДВОРЯНСКОЙ СЛУЖБЫ, НЕОБХОДИМОСТЬ « ПОСЛАБЛЕНИИ» КРЕСТЬЯНСКИХ ПОДАТЕЙ И Т.Д.).

80. СМ. ЧЕРНИКОВ, « СОСТАВ И ОСОБЕННОСТИ...», с. 277. ПО ДАННЫМ Б. МИХАН-УОТЕРС, ИНОСТРАНЦЫ ЯВЛЯЛИСЬ САМОЙ «ПОЛИТИЧЕСКИ ИНЕРТНОЙ» ГРУППОЙ (Meehan-Waters, Autocracy and Aristocracy, c. 156-157).

81. В БОЛЬШИНСТВЕ ЕВРОПЕЙСКИХ АРМИЙ ИСПОЛЬЗОВАЛОСЬ ПРОИЗВОДСТВО ПО СТАРШИНСТВУ. БАЛЛОТИРОВКА В ПЕРВЫЙ ОБЕР- И ШТАБ-ОФИЦЕРСКИЙ ЧИНЫ, ВВЕДЕННАЯ ПЕТРОМ I, ИСПОЛЬЗОВАЛАСЬ И ВПОСЛЕДСТВИИ (КРОМЕ ПЕРИОДА 1726-1731 ГГ., КОГДА ОНА БЫЛА УПРАЗДНЕНА ИЗ-ЗА МНОГОЧИСЛЕННЫХ НАРУШЕНИЙ - ПОДКУП, ДАВЛЕНИЕ СО СТОРОНЫ КОМАНДИРОВ, СПАИВАНИЕ, ПОДЛОГИ И Т.Д.). ПО ПОДСЧЕТАМ Г.В. КАЛАШНИКОВА, В 1725-1745 ГГ. ПОВЫШЕНИЕ В ПЕРВЫЙ ОБЕР-ОФИЦЕРСКИЙ ЧИН « ПО ДОСТОИНСТВУ» (РЕШЕНИЕМ ГЕНЕРАЛИТЕТА) ПРИМЕНЯЛОСЬ ПОЧТИ В 9 РАЗ ЧАЩЕ, ЧЕМ БАЛЛОТИРОВКА. - Г.В. КАЛАШНИКОВ, ОФИЦЕРСКИЙ КОРПУС РУССКОЙ АРМИИ В 1725-1745 ГГ., ДИСС. ... КАНД. ИСТ. НАУК, СПБ., 1999, С. 200-201, 206-209. СМ. ТАКЖЕ : С.М. ТРОИЦКИЙ, РУССКИЙ АБСОЛЮТИЗМ И ДВОРЯНСТВО В ХVIII В., М., 1974, С. 124-125.

82. ЗДЕСЬ И НИЖЕ УКАЗАНА ДОЛЯ В СОСТАВЕ ЧИНОВ РУССКОГО ПРОИСХОЖДЕНИЯ (БЕЗ ИНОЗЕМЦЕВ).

83. О ЗАВИСИМОСТИ ТИПА КАРЬЕРЫ СЛУЖИЛОГО ЧЕЛОВЕКА ОТ ЕГО ПРОИСХОЖДЕНИЯ СМ. ТАКЖЕ : С.В. ЧЕРНИКОВ, «ПРАВЯЩАЯ ЭЛИТА РОССИИ 1725-1730 ГОДОВ : ЧИСЛЕННОСТЬ, СОЦИАЛЬНЫЙ СОСТАВ, ОСНОВНЫЕ ТЕНДЕНЦИИ РАЗВИТИЯ», ВЕСТНИК ЧЕЛЯБИНСКОГО ГОСУДАРСТВЕННОГО УНИВЕРСИТЕТА, № 12, 2014, С. 32-33.

84. Kivelson, « Kinship Politics...», p. 22-23.

85. СМ. АНАЛИЗ СОСТАВА УЧАСТНИКОВ « ШЛЯХЕТСКОГО ДВИЖЕНИЯ» В РАБОТАХ И.В. КУРУКИНА. АВТОР ПРИХОДИТ К ВЫВОДУ, ЧТО ЭТИ МОДЕЛИ НЕ ВСЕГДА «РАБОТАЮТ В КОНКРЕТНЫХ СИТУАЦИЯХ», А ПОПЫТКИ СВЕСТИ СОБЫТИЯ НАЧАЛА 1730 Г. ИСКЛЮЧИТЕЛЬНО К КЛАНОВОЙ ПОЛИТИКЕ» ИЛИ БОРЬБЕ «ГРУПП» НАРЫШКИНЫХ-САЛТЫКОВЫХ И ДОЛГОРУКОВЫХ ЯВЛЯЮТСЯ «ОДНОСТОРОННИМИ» И ННЕДОСТАТОЧНО АРГУМЕНТИРОВАННЫМИ». -КУРУКИН, ЭПОХА « ДВОРСКИХ БУРЬ..., С. 30, 190-191 ; КУРУКИН, ПЛОТНИКОВ, 19 ЯНВАРЯ - 25 ФЕВРАЛЯ 1730 ГОДА..., с. 73-75.

86. КУРУКИН, ПЛОТНИКОВ, 19 ЯНВАРЯ - 25 ФЕВРАЛЯ 1730 ГОДА..., с. 204. ТО, ЧТО « ПРОЕКТ СЕКИОТОВА» НЕ УПОМИНАЕТ О НЕОБХОДИМОСТИ УТВЕРЖДЕНИЯ ИЗБРАННЫХ КАНДИДАТОВ, ОБРАТИЛ ВНИМАНИЕ ЕЩЕ КОРСАКОВ (Д.А. КОРСАКОВ, ВОЦАРЕНИЕ ИМПЕРАТРИЦЫ АННЫ ИОАННОВНЫ, КАЗАНЬ, 1880, С. 162). КАК УСТАНОВИЛ Г.А. ПРОТАСОВ, ЗА « ПРОЕКТОМ 364-Х» И НАИБОЛЕЕ РАДИКАЛЬНЫМ «ПРОЕКТОМ ОБЩЕСТВА», ПРЕДЛАГАВШИМ ЛИКВИДАЦИЮ ВЕРХОВНОГО ТАЙНОГО СОВЕТА, СТОЯЛ ОДИН И ТОТ ЖЕ КРУГ ЛИЦ. ЭТУ ТОЧКУ ЗРЕНИЯ РАЗДЕЛЯЕТ И.В. КУРУКИН. Г.А. ПРОТАСОВ, « ВЕРХОВНЫЙ ТАЙНЫЙ СОВЕТ И ЕГО ПРОЕКТЫ 1730 ГОДА (ИСТОЧНИКОВЕДЧЕСКОЕ ИЗУЧЕНИЕ)», ИСТОЧНИКОВЕДЧЕСКИЕ РАБОТЫ, ВЫП. 1, ТАМБОВ, 1970, С. 83 ; ОН ЖЕ, « ДВОРЯНСКИЕ ПРОЕКТЫ 1730 ГОДА...», С. 73-74 ; КУРУКИН, ПЛОТНИКОВ, 19 ЯНВАРЯ - 25 ФЕВРАЛЯ 1730 ГОДА..., C. $47-49$.

87. О ПОДПИСАНИИ ПРОШЕНИЯ 25 ФЕВРАЛЯ 1730 Г. СМ. : КУРУКИН, ПЛОТНИКОВ, 19 ЯНВАРЯ - 25 ФЕВРАЛЯ 1730 ГОДА..., С. 107, 143-147.

88. Сь. РИО, т. 66, С. 136. 
89. J. LeDonne, «Ruling Families in the Russian Political Order, 1689-1825», Cahiers du Monde russe et soviétique, 28 (3-4), 1987, с. 306-308.

90. ОБ УРОВНЕ «ПОЛИТИЧЕСКОЙ ГРАМОТНОСТИ» УЧАСТНИКОВ СОБЫТИЙ СМ.: КУРУКИН, ПЛОТНИКОВ, 19 ЯНВАРЯ - 25 ФЕВРАЛЯ 1730 ГОДА..., с. 76-89, 93.

91. ПО НАБЛЮДЕНИЯМ АНГЛИЙСКОГО РЕЗИДЕНТА К. РОНДО, ВНЕШНЕЙ ПОЛИТИКОЙ ЗАНИМАЛСЯ А.И. ОСТЕРМАН, А «ДЕЛА ВНУТРЕННИЕ, НАЗНАЧЕНИЯ И ОТЛИЧИЯ» «ВЕДАЛИСЬ» КЛАНОМ ДОЛГОРУКОВЫХ, СРЕДИ КОТОРЫХ ОСОБОЕ ВЛИЯНИЕ НА МАЛОЛЕТНЕГО ГОСУДАРЯ ИМЕЛИ А.Г. ДОЛГОРУКОВ И ЕГО СЫН ИВАН - ОБЕР-КАМЕРГЕР И ФАВОРИТ ПЕТРА ІІ (СБ. РИО, Т. 66, С. 47-48, ДОНЕСЕНИЕ ОТ 30 МАЯ 1729 Г.). ОСТЕРМАН ТАКЖЕ ЯВЛЯЛСЯ ВОСПИТАТЕЛЕМ ПЕТРА И ОБЕР-ГОФМЕЙСТЕРОМ ЕГО ДВОРА (СБ. РИО, Т. 94, С. 503, 507 ; Т. 101, С. 434), А В ДЕЛАХ МЕЖДУ ВЕРХОВНЫМ ТАЙНЫМ СОВЕТОМ И СЕМЕЙСТВОМ ДОЛГОРУКОВЫХ ОН НЕРЕДКО ВЫСТУПАЛ НЕОФИЦИАЛЬНЫМ ПОСРЕДНИКОМ. СМ. ТАКЖЕ : СБ. РИО, Т. 5, С. 312-313; А.Г. БРИКНЕР, « РУССКИЙ ДВОР...», ВЕСТНИК ЕВРОПЫ, 1896, КН. ІІІ (МАРТ), С. 7-16.

92. ОЧЕВИДНО, АВТОРСТВО « САМОДЕРЖАВНОГО ПРОШЕНИЯ» ПРИНАДЛЕЖАЛО НЕ ГВАРДЕЙЦАМ (АКТИВНЫМ УЧАСТНИКАМ СОБЫТИЙ 25 ФЕВРАЛЯ 1730 Г.), А « БОЛЕЕ ГРАМОТНЫМ И СТАРШИМ ПО ЧИНУ ПЕРСОНАМ» - СОСТАВИТЕЛЯМ «ШЛЯХЕТСКИХ ПРОЕКТОВ» (КУРУКИН, ПЛОТНИКОВ, 19 ЯНВАРЯ - 25 ФЕВРАЛЯ 1730 ГОДА..., С. 101-109). СМ. ТАКЖЕ : А.Б. ПЛОТНИКОВ, « ОГРАНИЧЕНИЕ САМОДЕРЖАВИЯ В РОССИИ В 1730 Г. : ИДЕИ И ФОРМЫ», ВОПРОСЫ ИСТОРИИ, № 1, 2001, С. 66-67.

\section{RÉSUMÉS}

L'article examine les causes du «mouvement nobiliaire » du début de l'année 1730 - formation spontanée de groupes de petite et moyenne noblesses qui avaient rédigé des projets de réformes politiques et administratives de l'État et les avaient soumis au Conseil suprême privé. Pour l'auteur, ce mouvement trouve essentiellement son origine dans les changements radicaux survenus dans la structure du pouvoir lors du règne précédent, celui de Pierre II. L'analyse d'un important corpus de sources publiées et inédites permet de démontrer toute l'imprécision de la conception historiographique traditionnelle qui réduit les tensions politiques à l'opposition entre la «nouvelle noblesse » et « le parti vieux-russe » et ne reflète pas l'étendue des transformations politiques qui ont affecté l'élite. En réalité, le renforcement de l'aristocratie (cela n'a en fait touché que quelques-unes des grandes familles) ne s'est véritablement constaté qu'au sein du Conseil suprême privé et du Sénat, tandis qu'au niveau exécutif, dans les capitales comme en province, les représentants des familles élevées aux grades de la Douma au XVII ${ }^{\mathrm{e}}$ siècle étaient supplantés par une noblesse moscovite d'extraction encore plus modeste et par des étrangers.

The article examines the causes of the "nobility movement" of early 1730 - a spontaneous grouping of members of the lower and intermediate nobility who wrote and submitted to the Supreme Privy Council proposals for governmental reform. The author considers that the origins of the movement lie essentially in the radical changes that took place in the Russian state apparatus in the preceding reign, that of Peter II. Analysis of an important corpus of both published and unpublished sources allows one to demonstrate that historiography's traditional interpretation reducing political tensions to an opposition between the "new nobility" and the "old-Russian" party has failed to show the full range of political changes affecting the elite. In reality, the strengthening of the nobility - which actually only concerned a limited number of 
families - has only been observed in the Supreme Privy Council and the Senate. However, in executive branches of government at both central and provincial levels, non-titled Duma families of the seventeenth century were supplanted by lesser Muscovite aristocrats and foreigners. The author demonstrates that the widespread approval met by the proposals of the "majority" did not rest on patronage networks but rather on the nobility's massive support of their main proposition to strip the Supreme Privy Council of its control over elections to higher governmental institutions at both central and local levels. The appendix lists the names of central and local administration heads in the years 1725-1730.

\section{AUTEUR}

\section{SERGEJ V. CERNIKOV}

ЛИПЕЦКИЙ ГОСУДАРСТВЕННЫЙ ТЕХНИЧЕСКИЙ УНИВЕРСИТЕТn, Université technique d'État de Lipetsk.zserg72@gmail.com 